Review

\title{
Chemistry of solid metal-based inks and pastes for printed electronics - A review
}

\author{
Clara Cano-Raya*, Zlatan Z. Denchev, Sílvia F. Cruz, Júlio C. Viana \\ Institute for Polymers and Composites, Department of Polymer Engineering, University of Minho, Guimarães 4800-058, Portugal
}

\section{A R T I C L E I N F O}

\section{Article history:}

Received 26 November 2018

Received in revised form 7 February 2019

Accepted 20 February 2019

\section{Keywords:}

Solid metal-based inks

Printed electronics

Post-printing methods

Solvent-based and polimerizable

formulations

\begin{abstract}
A B S T R A C T
Printed electronics, PE, is one of the fastest growing technologies in the world; it allows the construction of electronic devices in low-cost flexible substrates by printing techniques (e.g., screen, gravure, offset, flexography and inkjet printing) traditionally used in several industries (e.g., graphics arts, textiles, polymers). In PE, ink pigments are replaced by metallic particles or precursors that impart the electrical conductivity to the resultant printed patterns. This work reviews the available solid metal formulations used for conductive inks and pastes, focusing on both metallic particles and polymeric components. The influence and technical requirements of most commonly used printing techniques, along with the postprocessing treatments to reach the aim performance in the resultant inks has been addressed. Considering that PE is an emerging profitable field with novel applications in radio frequency identification (RFID) tags, thin-film transistors (TFT), light-emitting diodes (LED), transparent conductive electrodes (TCE) and organic solar cells (OSC), among others, it is crucial to know how printed formulations work and how they can be molded to fulfill the applications requirements. In this review, apart from metallic solid particles that has been widely reviewed in the past, the chemistry of polymer matrices has been focused in order to elucidate its important role in resultant inks performance. Novel outstanding formulations, such as reactive or metal-organic-decomposition (MOD) inks, have been presented.
\end{abstract}

(c) 2019 Elsevier Ltd. All rights reserved.

\section{Contents}

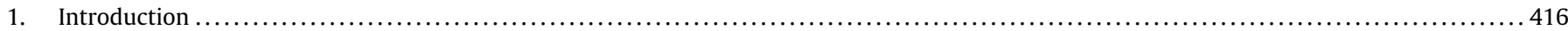

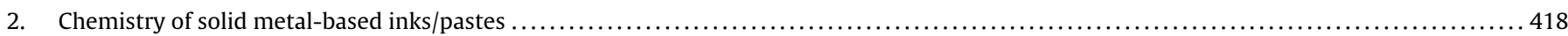

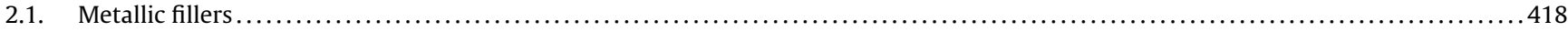

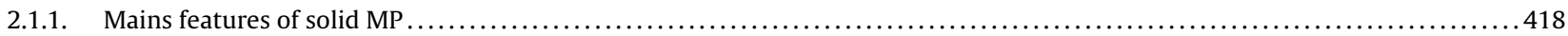

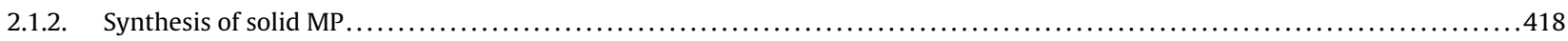

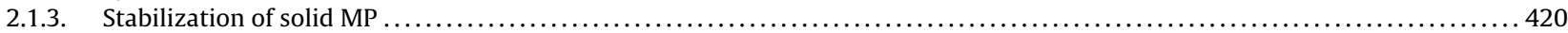

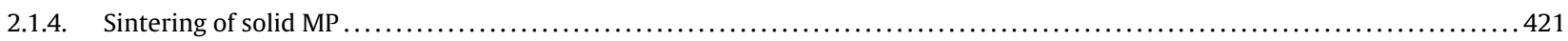

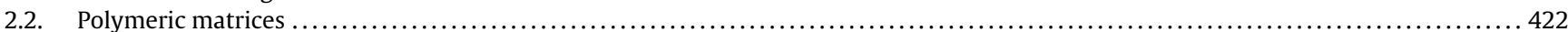

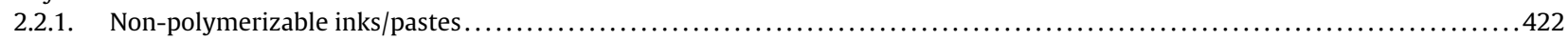

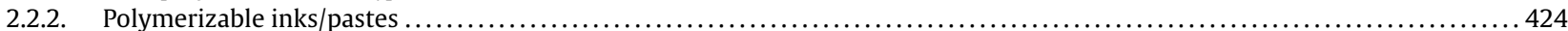

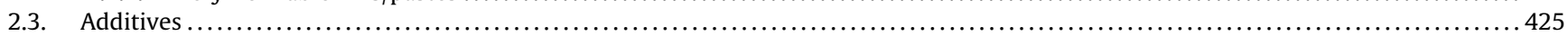

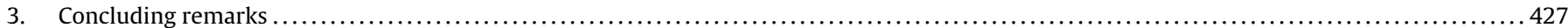

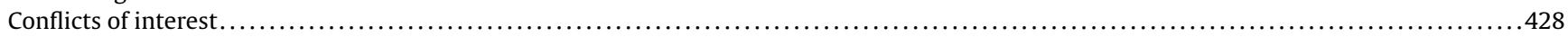

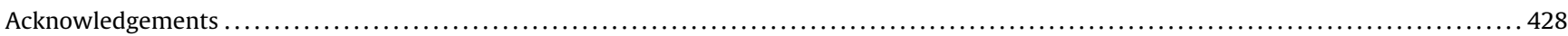

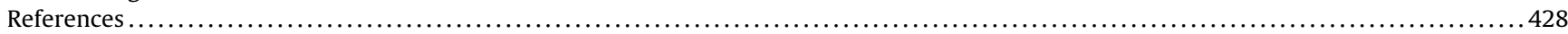

\section{Introduction}

Printed electronics (PE) refers to the technology that allows the fabrication of an electronic device through a printing process and to the respective devices manufactured in such way. PE is an

* Corresponding author.

E-mail address: claracano@dep.uminho.pt (C. Cano-Raya). expanding market that is expected to grow nearly $\$ 8.5$ billion in 2029 [1]. It appeared as a solution to pollutant and time-consuming 
Table 1

Glass transition temperatures of most commonly used polymeric substrates in printed electronics.

\begin{tabular}{ll}
\hline Plastic substrate & $T_{\mathrm{g}}\left({ }^{\circ} \mathrm{C}\right)$ \\
\hline Polyethylene terephthalate, PET & 70 \\
Polyethylene naphthalate, PEN & 120 \\
Polycarbonate, PC & 150 \\
Polyarylate, PAr & 215 \\
Polyethersulphone, PEI & 220 \\
Polyimide, PI & 270 \\
Fluorene polyester, FPE & 340 \\
Polynorbornene, PN & 340 \\
\hline
\end{tabular}

deposing/etching techniques traditionally used as circuits-making method [2]. Printing technologies are revolutionizing the electronic field by providing cost-effective manufacturing, allowing new applications now possible thanks to new formulations that are processed at temperatures compatible with flexible polymeric substrates (Table 1), otherwise impossible with conventional manufacturing technologies of rigid materials, such as printed circuit board (PCB) being most frequently made of glass-reinforced epoxy laminate FR4, or wafer materials (e.g., silicon, alumina).

The PE technologies are divided in contact techniques (e.g., flexography, gravure printing and soft lithography techniques), in which the printing plate is in direct contact with the substrate and, non-contact techniques (e.g., screen printing, aerosol printing, inkjet printing, laser direct writing), where only the inks get in contact with the substrate (Fig. 1). Screen-printing, flexography, gravure printing and soft lithography, are the most common used technologies by the electronic manufacturing industry.

Each printing technology is selected according to the type of electronic application (e.g., small, thin, lightweight, flexible and
Table 2

Required rheological properties for printing formulations (inks/pastes).

\begin{tabular}{lll}
\hline Printing technique & Viscosity (Pas) & Surface tension $(\mathrm{mN} / \mathrm{m})$ \\
\hline Screen-printing & $0.5-5$ & $38-47$ \\
Flexography & $0.01-0.5$ & $14-23$ \\
Inkjet printing & $0.001-0.1$ & $15-25$
\end{tabular}

disposable, etc.) to be fabricated, the production cost and volume [3]. Due to the wide range of printing technologies, the materials (inks/pastes and substrates) must meet certain requirements, depending on the type of printing technology being used and the final application. The coating material, commonly presented in the form of solutions with specific rheological characteristics (viscosity, surface tension, etc.), should be adapted to the printing technology to be thinner (ink) or thicker (paste) depending on the printing technology requirements (Table 2 ). In addition, they should be easily printed in a large variety of substrates, being possible to modify substrates surface in order to improve inks wetting and resultant ink adhesion [4].

Numerous reviews and books have been already published considering the different printing technologies [5-10]. The printable solutions may be solvent-based (aqueous or organic) or solventfree energy curable, with high variations of the viscosity and of the surface tension (Table 2). For screen-printing, the paste viscosity must be between $0.5-5$ Pa s and $38-47 \mathrm{mN} / \mathrm{m}$ of surface tension, while for flexography the ink viscosity is between 0.01-0.5 Pa.s and $14-23 \mathrm{mN} / \mathrm{m}$ of surface tension. In the case of non-contact techniques, viscosity frequently goes from 0.001 to $0.1 \mathrm{~Pa}$ s and surface tension from 15 to $25 \mathrm{mN} / \mathrm{m}$ in the inkjet printing case.

As in graphic arts, functional inks used in PE consist of a mixture of pigments, polymers, solvents, and additives. In the particular

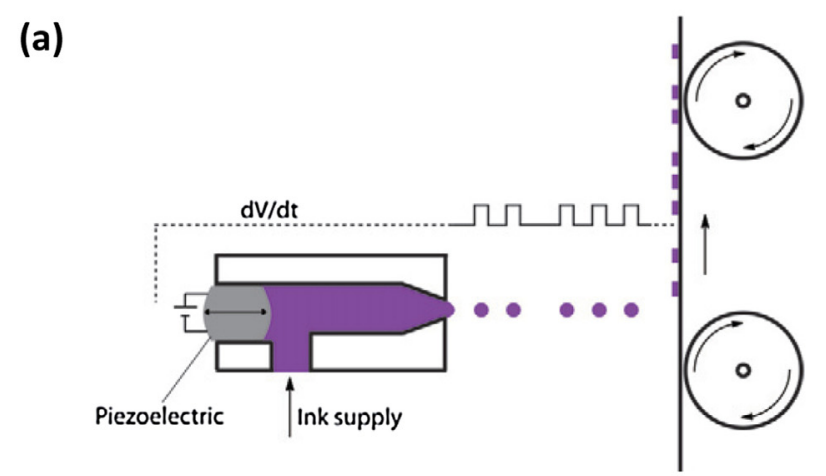

(c)

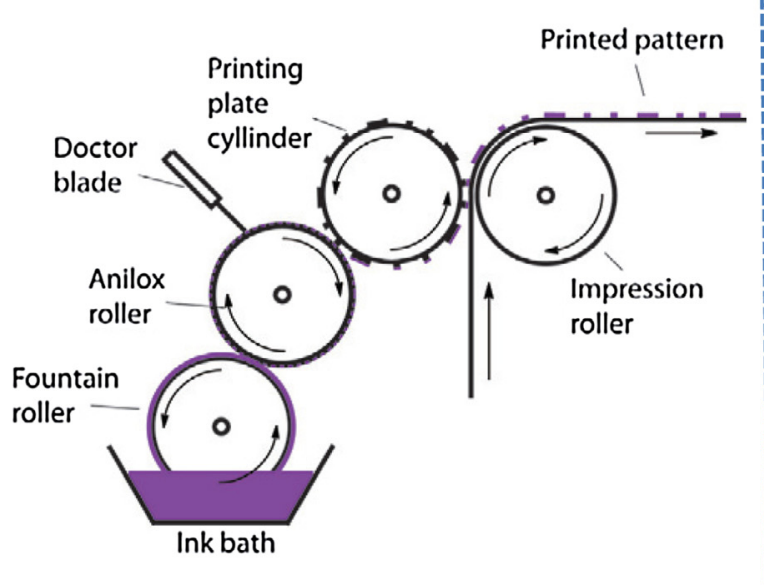

(b)

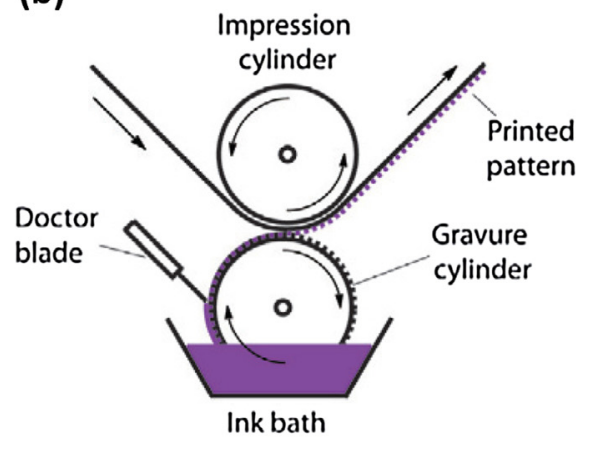

(d)
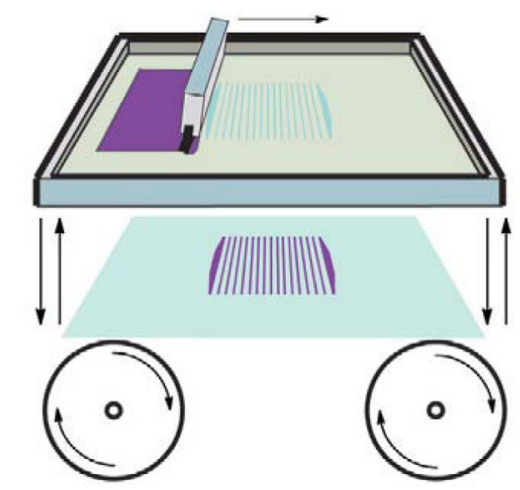

Fig. 1. Schematic representation of main printing technologies used in PE: (a) inkjet printing; (b) gravure printing; (c) flexographic printing; (d) screen-printing. Reproduced with permission [10]. Copyright @ 2012, Elsevier. 
case of conductive inks, pigments are replaced by metal particles or metal precursors that impart the electrical conductivity, which distinguish them from common inks [6]. Frequently, conductive inks are formulated by blending highly conductive micro or nanoscaled solid metal particles [11-14], being also possible to use non-metallic fillers (i.e., carbon nanotubes [15], graphene [16]). Additionally, the use of intrinsically conductive polymers have been described in some cases but the resultant conductivity is still far from that obtained when metallic fillers are used [17]. In the recent years, liquid metal inks have emerged as a powerful tool for direct printing of flexible electronics at room temperature $[18,19]$. They are composed by low melting point metals or its alloys that remain liquid at ambient conditions. In most of the cases, they are galliumbased and indium-based alloys with melting points below $100^{\circ} \mathrm{C}$ $[20,21]$. In liquid metal inks, gallium oxide skin enables gallium alloys to behave like a solid material with elastic properties until a critical surface stress is applied, above which makes flow starts readily [22]. This is in contrast to solid metallic fillers, where oxidation has undesirable effects. Therefore, in liquid metal inks, the rheological properties and the printability conditions are mainly governed by the liquid metal nature and not by a polymer component, as it is in solid metal-based inks. For this reason, liquid metal inks fall out of the scope of this review, which focuses specifically on the chemistry of solid metal-based inks highlighting the role of polymers as metallic fillers vehicle.

Polymers are crucial in inks formulations to promote a good dispersion and avoid agglomeration of the solid metal particles. Commonly, the metallic particles are stabilized in the ink solutions by organic ligand shells. The particles are treated with an organic material called capping agent preventing particles agglomeration and oxidation. This capping agent should be removed after printing through post-processing treatments to allow physical contact between metal particles in order to form continuous path connectivity. Different post-processing treatments have been used, i.e., sintering, annealing or simply drying in air, depending on the type of developed formulation. The right choice of post-processing treatment is essential because it defines the final morphology, its chemical, electrical and physical performance, the reliability of printed layers over time, and the manufacturing time [23].

In this review, we focus in the chemistry of solid metal-based inks/pastes used in PE, considering not only the metallic particles, that have been widely reviewed in the past, but also the no less important polymeric matrix. Solvent-based and energy curable formulations have been considered, establishing the differences between their chemistry, taking into account not only the printing conditions but also the available post processing methods that could be selected in order to reach the suitable performance for the predetermined application.

\section{Chemistry of solid metal-based inks/pastes}

The main components of solid metal-based inks are:

- the solid metal particles, MP (or their precursors) that will act as conductive fillers;

- the polymers as dispersing/capping agents that will ensure the binding of the printed ink to the substrate;

- the carrier solvents that will dissolve/swell up polymers; and

- other additives to enhance or modify the properties of the resultant ink.

In this section, individual ink components will be referred to.

\subsection{Metallic fillers}

\subsubsection{Mains features of solid MP}

Commonly, gold ( $\mathrm{Au}$ ) [24] and silver ( $\mathrm{Ag}$ ) [12] have been the most used metals in the fabrication of metal-based inks for PE. They are highly conductive noble metals that provide many advantages in conductive inks formulations. For example, Ag oxidizes but it does it slowly and forms a conductive oxide layer not affecting substantially the ink conductivity over time [25]. For this reason, silver-based inks have been commercialized by different companies (Henkel, DuPont, DycoTec, NovaCentrix, etc.) all over the world. Taking into account that the solid metal-based inks contain high metal loadings (above $20 \mathrm{wt} . \%$ ), the current challenge is to substitute silver particles by other cheaper conductive metals, such as, copper $(\mathrm{Cu})$ [13], aluminum $(\mathrm{Al})$ [26] or nickel ( $\mathrm{Ni}$ ) [27]. They are the low-cost alternative to silver inks, but they are not very stable against oxidation and form insulating oxides that could affect seriously the inks conductivity. Therefore, post processing methods often need to be carried out in vacuum or under a protective or reducing atmosphere in order to avoid oxidation.

Apart from the metal type, metal loading is another important factor to be considered in the construction of effective conducting paths through the whole printed pattern. When a sufficient amount of filler is loaded, the filler particles get closer and form conducting paths providing electrical conductivity. The corresponding filler content is called percolation threshold. In this concentration range, the conductivity changes drastically by several orders of magnitude for small variations of filler content. Whereas, at high loading of the filler, the increasing number of conducting paths can form a three-dimensional network that will provide high conductivity that is less sensitive to small changes in the filler content [28]. Inks based on solid metal particles usually contain metal loadings of about 20-60 wt.\% [29], being possible to reach even higher loadings in screen-printed pastes [30] due to less-demanding viscosity constraints.

Other important factors that have strong influence in the resultant conductivity of printed inks are the morphology and the size of the metallic particles. In this sense, the percolation behavior can be drastically influenced by the shape of the filler, being proved that fibers show a percolation threshold of only several percent [28]. As a rule, particles with an aspect ratio larger than one will be preferred avoiding, therefore, spherical particles and selecting more efficient shapes, such as fibers and flakes. In some cases, a conjunction of different shapes and sizes has been described in order to multiply contact points and enhance packaging efficiency $[31,32]$ (Fig. 2).

Concerning particles size, it has been described that the inks resistivity decreases for increasing the particles size due to the fact that larger contact areas are created between larger particles [28]. Nevertheless, particles size strongly depends on the printing technique used to deposit the printed patterns. For example, in inkjet printing the use of nanosized particles is mandatory in order to avoid clogging and blockage of print-head nozzles [29]. On the other hand, screen-printing, which is widely used in PE, allows the use of microsized particles. Therefore, depending on the printing technique, effective post-processing treatments should be used in order to ensure the formation of enough contact areas between metal particles, especially in the nano-inks where remaining insulating compounds can affect seriously the resulting electrical conductivity of printed path.

Main features of solid metallic particles have been summarized in Fig. 3.

\subsubsection{Synthesis of solid MP}

Considering the synthesis of solid metal particles used as conductive fillers, different methods of production have been found 

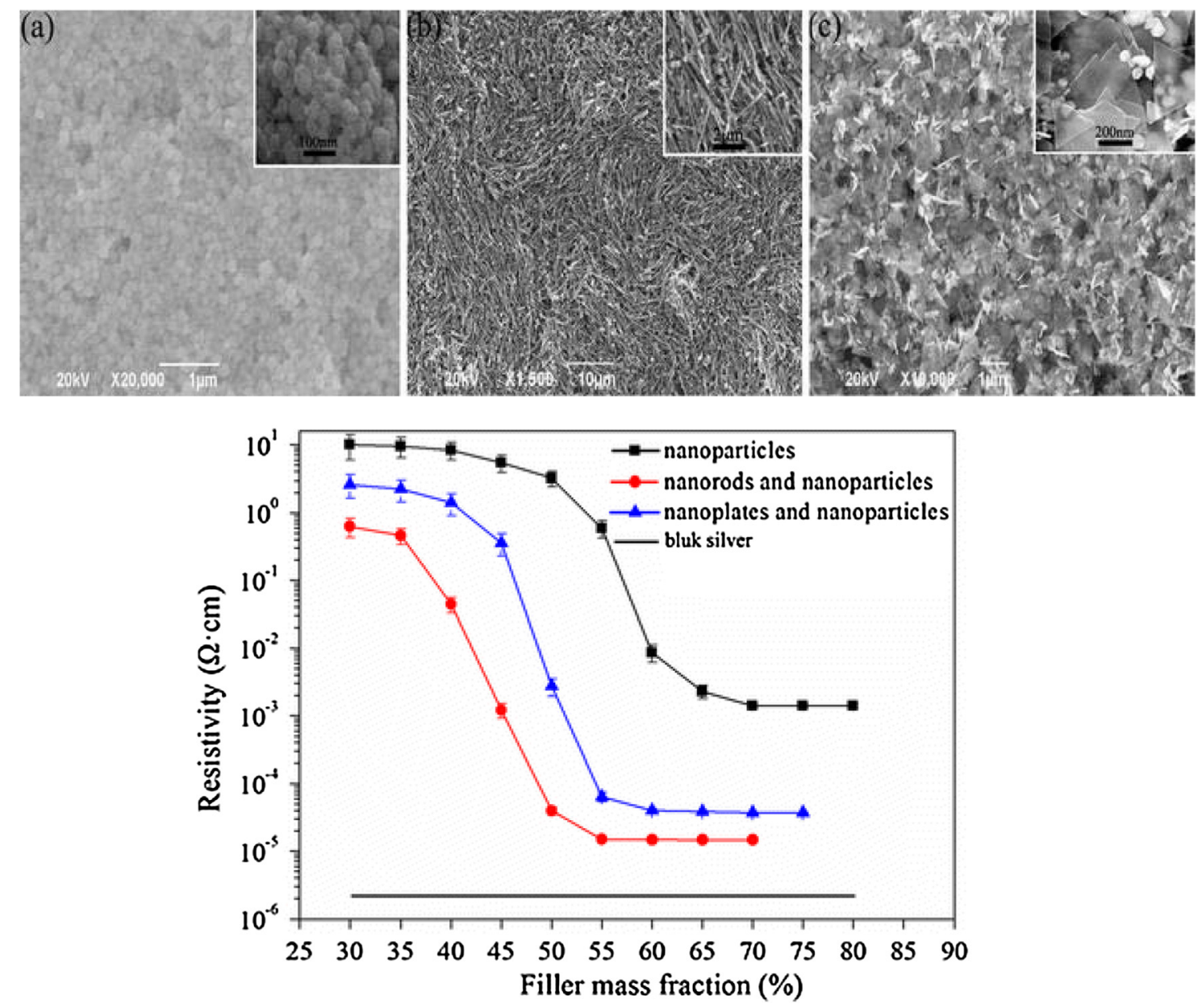

Fig. 2. SEM images of inkjet printed tracks filled with silver nanoparticles (a), silver nanorods and nanoparticles (b), silver nanoplates and nanoparticles (c). Influence of filler content in resultant electrical resistivity (d).

Reproduced with permission from [32]. Copyright $\odot$ 2012, Springer Nature.

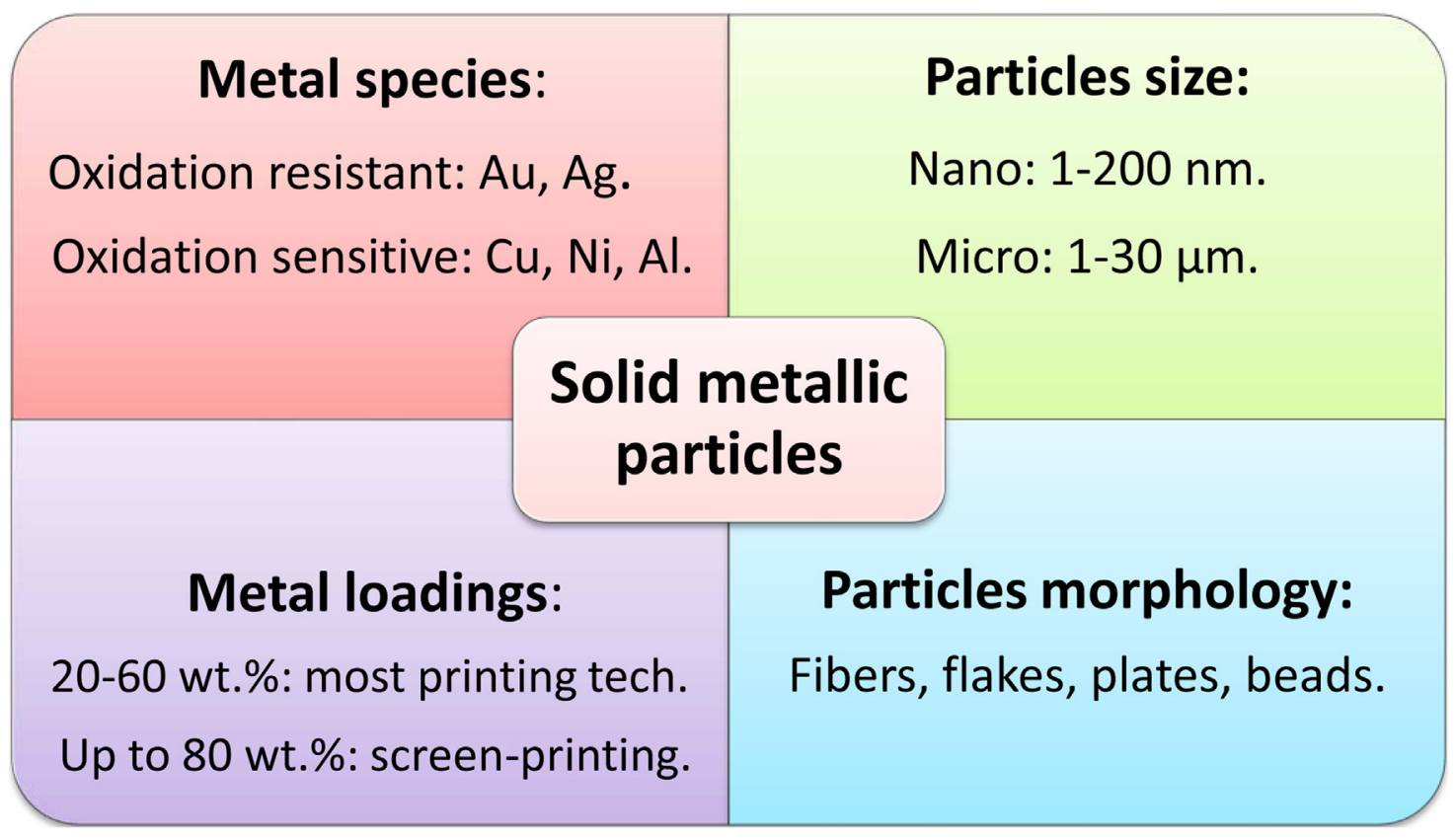

Fig. 3. Schematic representation of main features of solid metallic particles. 
in the literature. Larger particles with micrometric dimensions are usually produced by powder metallurgical processes that will be chosen taking into account the expected particles size and the purity of the produced metal powder [33]. They can be classified into different categories:

i) atomization processes that contain two individual steps: first, shearing of a molten metal occurs and, second, freezing of the liquid droplets takes place. Depending on the energy source used for shearing, the atomization processes can be divided into gas atomization, water atomization, centrifugal atomization and plasma atomization;

ii) rotating electrode process, consisting on the melting of a rotating electrode by using an electric arc or a hightemperature plasma, and subsequent shattering of resultant molten droplets;

iii) mechanical processes, where small particles are produced from larger particles by mechanical forces in a process called comminution that can involve techniques like crushing, grinding, and milling. Usually, the raw metals used in these mechanical processes are pre-treated to make them more brittle and, thus, increase the efficiency of the process; and

iv) chemical processes that produce the metal powders by the reduction of either metallic oxides or chlorides, precipitation from solution (hydrometallurgy), electrolysis, and thermal decomposition (carbonyl reactions).

Metal nanoparticles (MNP), usually used in inkjet printing formulations, are prepared by two main strategies: top-down and bottom-up methods [34].

Briefly, top-down methods break down bulk metals, or microscopic particles, to nanosized particles by physical procedures and disperse them into the proper liquid medium that usually contains a stabilizing agent. These methods present important disadvantages like being difficult to obtain uniform and stable MNP at large-scale production. Moreover, they are expensive, energy-consuming and require sophisticated equipment [35].

Bottom-up methods are chemical procedures that generate MNP from ionic precursors by reaction with a proper reducing agent in solution, and/or by the decomposition of precursor molecules [36]. They are produced in liquid medium, being possible to use polar and non-polar solvents, or even ionic liquids [37]. These chemical methods permit to control several properties like particles size and its distribution, morphology, stability toward aggregation and sedimentation. Recently, these bottom-up methods have been used to produce MNP directly in the core of the printed ink, giving rise to the so called reactive inks (explained hereinafter).

\subsubsection{Stabilization of solid MP}

Once metallic particles are produced, it is crucial to protect them against aggregation and oxidation, especially for nanosized particles that are more sensitive to these undesirable phenomena. Several stabilization mechanisms have been proposed against particles aggregation employing the use of surfactants and polymers to provide electrostatic, steric or electrosteric stabilization [29]. Electrostatic stabilization is based on the electrostatic repulsion between electrical double layers surrounding MP. Although this strategy is effective to obtain stable dispersions, high metal load destabilizes formulations and aggregation may happen. For this reason and taking into account that electrostatic mechanism is not effective in organic media with low dielectric constant; steric stabilization is used instead. In this case, stabilization is achieved by surrounding the particles with an adsorbed layer of bulky molecules, such as surfactants or polymers. Nonionic amphiphilic polymers, containing both hydrophobic and hydrophilic blocks, are the most effective steric stabilizers, being Poly( $N$-vinyl-2-pyrrolidone) (PVP) one of the most frequently used [38]. Furthermore, electrosteric stabilization is presented as a combination of electrostatic and steric mechanisms, being particularly effective in aqueous formulations. In this case, most used electrosteric stabilizers are: poly(acrylic acid) salts [39], carboxymethyl cellulose sodium salt [40], or polyethylenimine [41], among others.

Oxidation has two negative effects in the freshly produced metal particles: decrease on the resultant electrical conductivity and increase of the required temperature for sintering process. These effects are more serious in non-noble metals such as copper, aluminum and nickel. Several strategies have been proposed against oxidation:

i) production of metal particles in solvents with reducing properties like polyols [42]; octylamine [43];

ii) synthesis under inert atmosphere conditions [44];

iii) addition of antioxidants like ascorbic acid [45];

iv) use of capping agents like carboxylic fatty acids [43,44], surfactants [46], alkanethiols [47], and polymers such as poly(N-vinylpyrrolidone) (PVP) $[45,48]$ that has been widely used, not only to prevent particles aggregation but also as antioxidation protective agent.

In addition, the formation of core-shell bimetallic MNP using a noble metal for shell construction has been presented as a longlasting strategy against oxidation [49,50].

More information regarding MNP stabilization can be found in the review by Magdassi et al. about available routes to achieve oxidation stability [51].

More recently, a novel kind of metallic inks has been presented, called reactive inks or metal-organic-decomposition (MOD) inks that do not contain preset particles and are therefore highly transparent. In them, conductive metal particles are produced directly in the core of the printed patterns by means of a reduction reaction and/or by the decomposition of a metal-organic compound. As metal precursors, both inorganic salts and metal-organic compounds have been used. Inorganic salts such as copper sulfate pentahydrate $\left(\mathrm{CuSO}_{4} \cdot 5 \mathrm{H}_{2} \mathrm{O}\right)$ has been reduced by sodium phosphinate monohydrate $\left(\mathrm{NaH}_{2} \mathrm{PO}_{2} \cdot \mathrm{H}_{2} \mathrm{O}\right)$ to produce "fresh" copper particles [52]. However, most frequently, metal-organic compounds are preferred because they permit to increase the metallic content due to its better solubility in inks composition as compared to inorganic precursors [53]. Amine-based complexes, such as diamminesilver(I): $\left[\mathrm{Ag}\left(\mathrm{NH}_{3}\right)_{2}\right]^{+}$and bis(ethylenediamine)silver(I): [ $\left.\mathrm{Ag}\left(\mathrm{NH}_{2} \mathrm{CH}_{2} \mathrm{CH}_{2} \mathrm{NH}_{2}\right)\right]^{+}$carboxylates [54,55] have been used to produce elemental silver particles in the core of the printed inks. Traditionally, thermally induced decomposition and reducing agents like formic acid [55], hydroquinone [56], formaldehyde [57] or polyol solvents with reducing properties [53] have been used. Additionally, laser-induced decomposition and hybrid thermalphotonic curing have been presented as appropriate methods to process reactive inks [54,58], and novel metal-organic compounds with self-reducing properties has been synthesized [53,59].

The free-particle nature of MOD inks, makes them especially interesting for inkjet printing, being possible to use ultra-fine nozzles without clogging problems $[60,61]$. In this case, technology is called reactive inkjet printing (RIP) [62]. In some cases, the metal precursor and the reducing agent can be printed in a two-step process using a multi-color printing head $[63,64]$. In addition, these inks do not present oxidation problems because the metal precursor is already in its oxidized form [65]. This makes them very attractive although, in contrast, they do not provide high conductivities due to an insufficient content of such produced metal (about 15 wt.\%) that may imply tedious multi-time coating to achieve the aimed conductivity in some applications. Recently, some works 
(a)

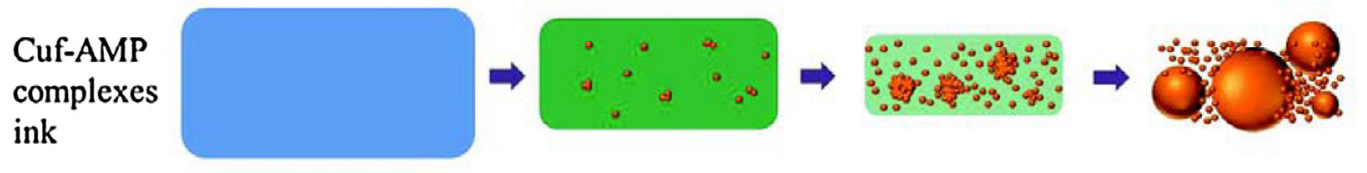

(b)

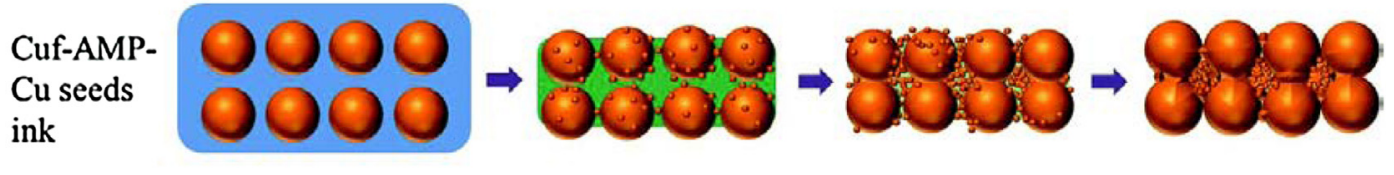
ink
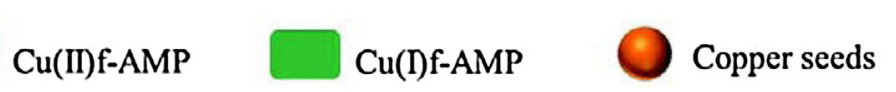

$\sum_{\infty}^{\infty}$ Copper nuclei
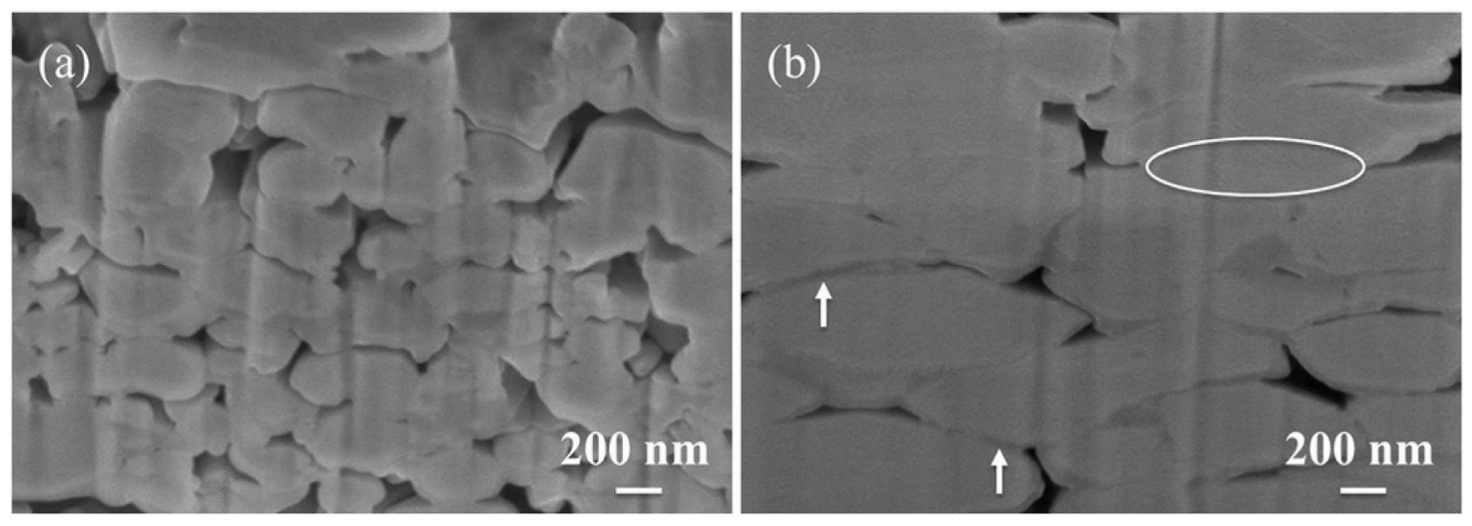

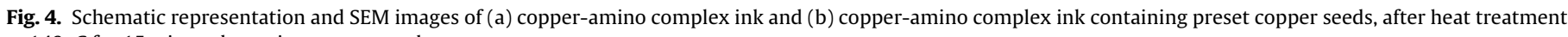
at $140{ }^{\circ} \mathrm{C}$ for $15 \mathrm{~min}$ under a nitrogen atmosphere.

Reproduced with permission from [66]. Copyright (c) 2016, Royal Society of Chemistry.

have been published in order to overcome this issue; they combine the use of metal microsized particles and metal precursor compounds that decompose during sintering process and give raise to freshly formed metal nuclei that promote better contact between isolated metal microparticles [66,67] (Fig. 4).

\subsubsection{Sintering of solid MP}

Finally, as an essential part in the formation of effective conductive paths, sintering processes are the responsible for welding the solid MP below their melting point [23]. Together with drying and curing, they are considered post-printing treatments.

Especially in metal-based nanoparticles inks, the presence of very fine (few nanometers) organic layer between the conductive particles is enough to block the movement of electrons from one particle to the others [11]. If this happens, the removal of this organic layer is mandatory to produce conductive patterns. For this reason, the selection of a proper sintering temperature in nanoparticle-based inks is extremely important for polymer electronic applications, in which materials such as PET [68], and PC [69], are widely used as substrates, but have low glass transition temperature (Table 1). In fact, sintering includes two different steps: removal of stabilizers and coalescence of solid MNP. The sintering temperature is mainly defined by the removal of the stabilizing molecules from the metal surface rather than the melting point depression due to a smaller particle diameter [70]. Such removal can be carried out by different strategies like decomposition, desorption, or evaporation of the material to enable close contacts between the particles in the dried printed patterns.

In traditional thermal sintering, the temperature (typically between 100 and $400^{\circ} \mathrm{C}$ ) where the nanoparticles form the percolation path must be below the softening temperature of the substrate and normally electrical conductivity is improved with the extension of sintering time [71] but, frequently, anti-oxidation protective conditions such as inert atmosphere [72] or vacuum [73] are required in order to ensure resultant conductive patterns. With the aim of turning sintering processes more efficient, current research is focused in the development of low temperature sintering methods that attempt to reduce the processing time to a few minutes, seconds or even a fraction of a second, while achieving similar or even better electrical conductivity values compared to conventional thermal sintering, minimizing particles oxidation effects with as low energy consumption and applied temperatures as possible [70]. Briefly, alternative sintering methods will be described.

Photonic sintering uses short pulses of an intense pulsed light source with a broad spectrum, ranging from the UV to the IR, to increase the temperature in the sample locally and rapidly. Due to the dark color of the silver nanoparticle inks and the transparency of the polymer foils, the light is only absorbed by the ink, hence creating a rapid temperature rise within the ink rather than in the polymer foil [74]. Sometimes, concomitant fillers, such as carbon nanotubes (CNT), can be added to inks formulations to improve the efficiency of photonic sintering by boosting the optical absorbance of the resultant ink due to the low reflectance and high absorbance of CNT over a broad wavelength range [75]. Normally, the polymer foil is not damaged by the photonic sintering process directly. However, the indirect heating caused by the dissipated heat from the ink to the substrate may cause damage. Therefore, carefully tuning the pulse length, the flashing frequency, the sintering time as well as the intensity of the lamp, should be made so that substrate damage remains very limited. Depending on the electromagnetic radiation used to provoke metals sintering, different photonic processes have been described, e.g., photonic flash sintering, IR sintering, laser sintering and UV assisted sintering [76-78]. In particular, photonic flash sintering has been described as a powerful anti-oxidation strategy able to trigger copper oxide reduction to produce copper 
conductive films in a short period of time ( $2 \mathrm{~ms})$ under ambient conditions $[79,80]$.

Plasma sintering is usually performed by the exposure of the printed patterns to low-pressure argon plasma. Plasma generation results in the formation of various excited species and UV irradiation, which causes decomposition of the organic components of the ink and enables direct contact between metal particles [34]. It is known that plasma sintering progresses from top to bottom in the structures and the time for full sintering to take place depends on the thickness of the sample. Long sintering times of up to $4 \mathrm{~h}$ has been described for the complete sintering of a $\mathrm{Ag}$ nanoparticles ink [74]. Due to its slow sintering velocity, plasma sintering is not recommended for large-scale printing techniques unless very thin layers are processed.

Microwave sintering is based on fast (seconds to minutes) heating of printed metal layer by applying microwave radiation. Since metals have a very small penetration depth $(1-2 \mu \mathrm{m}$ for Ag, Au, and $\mathrm{Cu}$ at $2.54 \mathrm{GHz}$ radiation), their sintering is successful only if the thickness of the printed layer is of the same order as the penetration depth. However, for metals such as Ag, with good thermal conductivity, the printed patterns will be heated uniformly enabling the microwave radiation to be applied to sintering patterns exceeding the penetration depth [34]. Nevertheless, although microwave sintering has been applied successfully in the laboratory, it is difficult to control sintering uniformity in large-scale productions.

In electrical sintering a voltage is applied across the printed region and that current flow causes local heating of the metallic layer. This sintering method requires the printed pattern to be slightly conductive before sintering. It is a quick process that can take place in a few milliseconds to seconds, providing conductivity values of up to $50 \%$ of bulk $\mathrm{Ag}$ [81].

Chemical sintering is based on desorption or decomposition of the protective layer on the surface of the MNP by chemical agents [34]. As decomposition method, the oxidation of 1-butanethiol stabilized Au nanoparticles has been described by Coutts et al. achieving sintering of the NP at room temperature (RT) [82]. Another approach has been the removal of dodecylamine as stabilizing agent in a Ag-based NP ink by dipping it into methanol [83].

As desorption method, Magdassi et al. presented an approach where the polycation of poly(diallyldimethylammonium chloride) (PDAC) caused immediate sintering of the silver NP stabilized by polyacrylic acid (PAA) sodium salt at RT, due to the neutralization of charges of stabilized particles and subsequent desorption of stabilizing agent [84]. In a following work, Grouchko et al. described the destabilization of PAA stabilized Ag NP by an increasing concentration of sodium chloride during drying of the ink [85] and subsequent coalescence of metallic NP. In a similar mechanism, desorption of the polymeric stabilizer has been achieved by the exposure of the printed patterns to $\mathrm{HCl}$ vapour [86] or solution [87].

Once metallic inks are sintered, the formulations which contain oxidation-sensitive metals, e.g., copper-based inks, might present poor long-term stability [88]. Therefore, in order to expand their practical applications in printed electronics, it is mandatory to improve the stability of the sintered printed patterns. In this sense, Paglia et al. developed a two-step deposition method to prevent the oxidation of the underlying layer improving the long-term stability of such sintered copper films [80]. Recently, Li et al. [89] studied the effect of the size of copper particles on the microstructure, conductivity and long-term stability of sintered copper films. They use submicron copper particles that are more resistant to oxidation. Additionally, in situ "fresh" copper nanoparticles are produced that act as nano-welders to increase the sintering efficiency. In conclusion, Li et al. stated that the long-term stability of sintered copper films is affected not only by the changes in chemical composition (emergence of copper oxide species), but also by the films microstructure evolution.

\subsection{Polymeric matrices}

In conductive inks, polymers are used as stabilizing agents to prevent the aggregation of metal particles acting also as capping agents that provide protection against oxidation. Moreover, the polymer component offers binding properties that ensure the attachment of the printed patterns to the substrate. This binding function may be a result of drying/evaporation of solvents included in inks formulations or may imply a polymerization reaction during ink curing. Depending on the underlying mechanism, solid metal-based inks can be classified into non-polymerizable and polymerizable.

\subsubsection{Non-polymerizable inks/pastes}

In this kind of inks, polymers are dissolved/swollen in a carrier solvent that provides the viscosity properties required for the printing process. They must be compatible with metallic fillers and should deliver the functional material to the substrate, ensuring the end-use performance of the printed ink. In general, a good solvent should possess the following characteristics [25]:

- To dissolve/swell the polymer;

- Not to dissolve/degrade the conductive filler;

- To evaporate at a rate compatible with desired printing process;

- Not to degrade the printed substrate;

- Compatibility with the image carrier (flexo plates, screens, etc.);

- To ensure required ink viscosity.

Depending on the type of solvent used for ink formulation, they can be classified into solvent-based (containing organic solvents) and water-based inks. The selection of the proper solvent is decided taking into account several factors, i.e., environmental and health issues, large-scale production, drying time, among others. It is usual to add co-solvents, which are compatible with the system, but do not dissolve the polymer. Co-solvents may be incorporated into inks for other reason, such as tailoring surface tension of the ink, or to modify its drying properties [90].

Traditionally, solvent-based inks are formulated using a wide variety of available organic solvents. One of the most popular ones has been the methyl-ethyl-ketone (MEK or butanone). It is a versatile solvent that has a fast dry time and dissolves many polymers and dyes [91]. However, it presents a strong odor that is very pronounced in large-scale productions, not fulfilling the requirements in volatile organic compounds (VOC) legislation. For this reason, it has been replaced by other solvents like aliphatic ether acetates, ether alcohols, diols and triols, cellosolves, carbitols and aromatic ether alcohols. These are hydrophilic solvents that reduce the formation of metallic clusters and avoid blockage and clogging problems in inkjet printing technology [92]. Among them, butyl carbitol has been widely used because it is a slow evaporating solvent that reduce printing defects and bubble formation during fast evaporation. It also increases lifetime stability of inks because its composition remains constant over time and also induces metal particles coalescence.

Polymers, in solvent-based inks, are selected considering the required properties of resultant printed patterns. Additionally, printing processability should be taken into account because, for instance, if the selected polymer has a low molecular weight, vast amounts of polymer should be added into formulation in order to achieve an adequate viscosity. This could be translated in an increase of the dry time of the ink and, in general, low concentrations of polymers are preferred in order to remove all or most of the organic material during the post-printing process. In contrast, using 

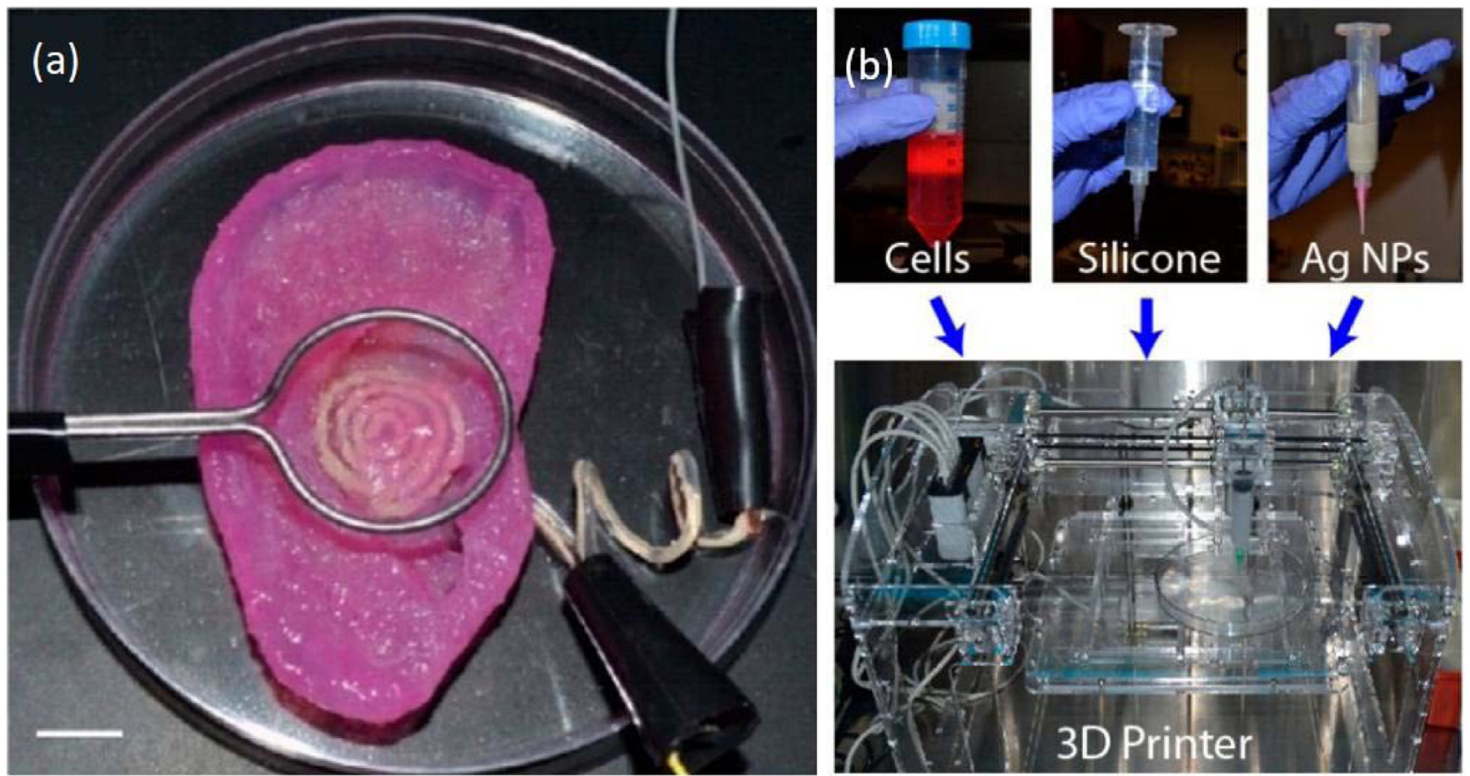

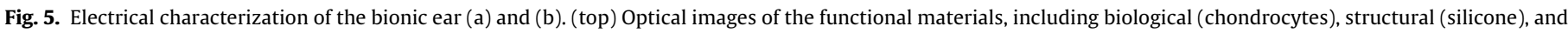
metal-based (Ag NP-formulation) used to form the bionic ear; (bottom) a 3D printer used for the printing process.

Reproduced with permission from [102]. Copyright @ 2013, American Chemical Society.

a polymer with high molecular weight could imply drawbacks in the printing quality due to the formation of unwanted satellites during drop break off in inkjet printing technology. Traditionally, nitrocellulose has been used in many formulations because it is an inexpensive polymer, with good adhesion to many substrates and with good durability [91]. However, numerous non-ionic and/or ionic polymers [92] could be used as well, polyvinylpyrrolidone (PVP) being among the most popular ones, not only as dispersant but also as capping agent $[93,94]$. Additionally, epoxy resins have been used in some applications to increase the adhesion strength via condensation reaction of the hydroxyl groups produced from the epoxide rings in the resin with oxygen atoms on the surface of glass substrates [95].

Different metallic fillers have been described in solvent-based formulations: for instance, silver microparticles $(1-40 \mu \mathrm{m})$ have been used in a screen-printable formulation for the construction of electronic devices, such as c-Si solar modules [96]. Formulations with low-cost conductive metals, such as $\mathrm{Cu}$ and $\mathrm{Ni}$ nanoparticles suspended in toluene and a high molecular weight polymer has been described for building flexible printed-circuit boards [97]. In a different approach, reactive solvent-based inks have been presented producing freshly metal NP in the core of the ink by decomposition of a precursor metal-organic complex or by the reduction of a precursor inorganic salt in formulations that contain a polymer binder [98] or just a mixture of different solvents $[64,67]$.

On the other hand, promoted by VOC legislation and health issues, water-based inks were presented as an alternative to polluting organic solvent-based formulations. In water-based formulations, two types of polymers can be found: such that form a real solution and other that do not dissolve completely in water and form a colloidal dispersion [25]. The former polymers dissolve in alkaline aqueous solution and present a lower degree of polymerization. Using this strategy, Hyun et al. presented a highlyloaded silver ink for screen printing on plastic substrates based on the use of poly(acrylic acid) (PAA) as capping/dispersing agent and diethanolamine as reducing agent with basic character [30]. In contrast, colloidal polymers have a higher degree of polymerization and represent long-chain polymers that provide optimal ink-film forming properties and stable ink viscosity. In this case, polymers like PVP [99] and cellulose derivatives [100,101] have been widely used. Additionally, biopolymers such as alginate hydrogel were used to construct the scaffold of a 3D-printed bionic ear with electronic functionality provided by a silver-based ink [102] (Fig. 5).

Depending on the monomers that are used to build up the polymer chains, different properties are imparted to the resultant ink [25]: (i) methyl methacrylate imparts water resistance, hardness, gloss retention and fast dry speed; (ii) styrene imparts water and block resistances, hardness, initial high gloss, poor gloss retention and fast dry speed; (iii) acrylic and methacrylic acids impart good adhesion, re-solubility, hardness and grease resistance; (iv) shortchain acrylates and methacrylates impart flexibility, stain and rub resistance; and (v) long-chain acrylates and methacrylates impart water resistance, flexibility and adhesion.

In water-based formulations it is also usual to mix water with other co-solvents like glycerol [44] or ethylene glycol [22], in order to reduce the surface tension and improve the evaporation rate of the aqueous ink.

As in organic solvent-based formulations, several metallic fillers have been used for aqueous formulations, from silver NP [30] and silver nanowires (NW) [101], to cheaper conductive fillers like copper NW [100]. Aqueous reactive ink formulations have been described as well, based on the decomposition of silver complexes $[61,103]$ and on the reduction of copper and nickel salts [63].

Post-printing processes in non-polymerizable formulations frequently involve the exposure of printed patterns to heat in order to remove the solvents. Especially, inks with low nanomaterials loads, high solvent contents, and low viscosities exhibit complex flow patterns during solvent evaporation, which tend to accumulate the solid functional nanomaterials at the edges of the structures, giving raise to the so-called "coffee ring effect" [104]. Although this is an undesirable effect that affects printing quality, Layani et al. managed to use it in the construction of a smart transparent array of interconnected conductive rings [105] (Fig. 6).

Frequently, heat treatment means sintering of MNP that present lower sintering temperature than larger microsized ones. However, thermal sintering should be carried out under inert ambient conditions in order to avoid the oxidation of metallic nanoparticles. 

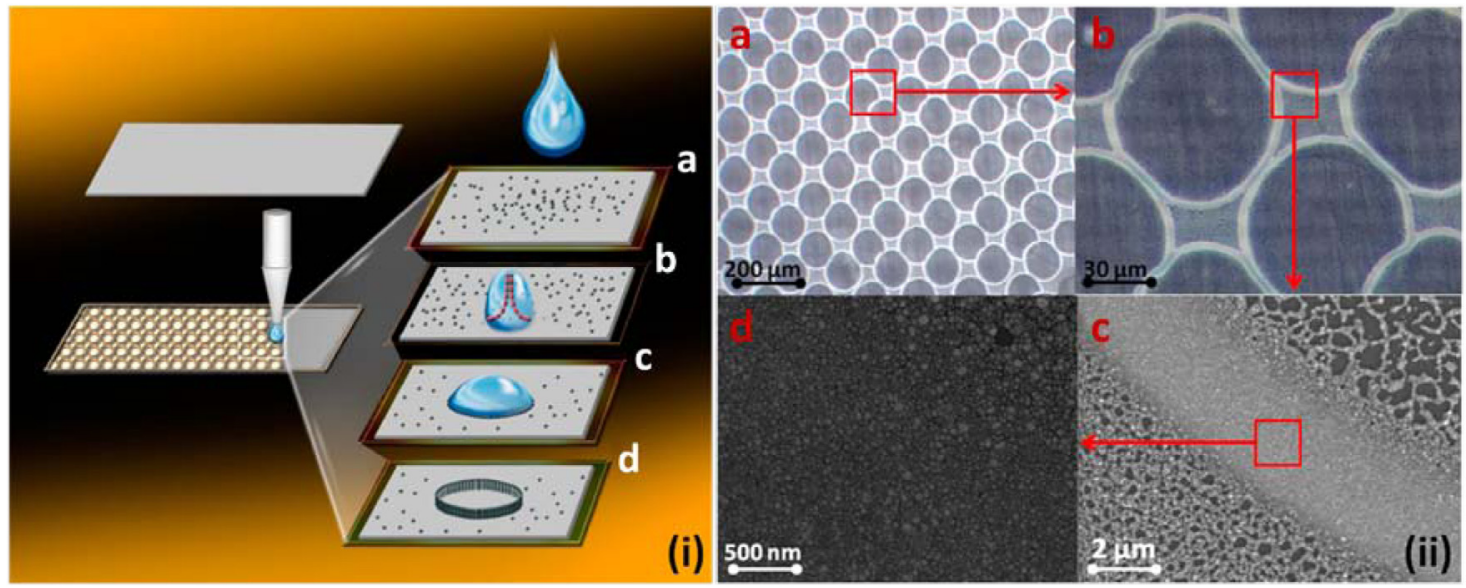

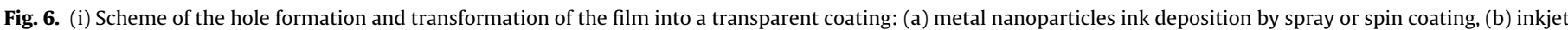

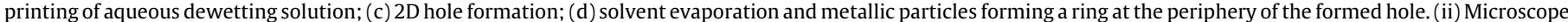
images ( $a$ and $b$ ) and HRSEM images ( $c$ and d) of connected conductive rings coated onto a glass substrate.

Reproduced with permission from [105]. Copyright @ 2014 , American Chemical Society.

As alternative, other available strategies, such as, photonic sintering, laser sintering, or low temperature chemical sintering could be used, as pointed out in the MP section (Section 2.1.4).

In general, water-based inks present worse adhesion, lower abrasion, heat and moisture-resistance than the best available organic solvent-based counterparts. For this reason, polymerizable formulations (described in the next section) present a better alternative to polluting organic solvent-based formulations, when good adhesion and abrasion durability are required.

Before moving forward to polymerizable inks, one special nonpolymerizable formulation shall be still depicted. These are hot melt inks, in which a thermoplastic polymer is heated up until melting before adding the conductive filler; this approach has been used by Kwok et al. to build up carbon black conductive filaments for 3D printing [106].

\subsubsection{Polymerizable inks/pastes}

Polymerizable inks involve a radical polymerization reaction that occurs during ink curing after the printing process. Initially, they were presented as solvent-free solutions whose introduction was encouraged by health and safety concerns, in addition to the environmental legislation controlling the emissions of VOC at high production volumes [107]. Moreover, due to the lack of a real solvent in these formulations, manufacturing and processing times related to solvent removal operations were reduced and fabrication defects due to non-homogeneous solvent evaporation and bubbles formation during curing were minimized [108].

Usually, polymerizable ink formulations contain: monomers/oligomers, initiators, solid metallic particles or their precursors and additives.

Monomers and oligomers form the polymer structure where the metallic particles are embedded. Most frequently, they are acrylates of different functionalities $[109,110]$ and it has been demonstrated that increasing the functionality of the acrylate will increase the cross-link density of the polymer, resulting in a harder, less flexible film that has a higher resistance to solvents, abrasion, and scratches [111]. Although, a higher cross-link density can cause lower adhesion to the substrate, it has been proved that it also promotes higher cure shrinkage that will result in a higher conductivity of the printed ink due to an increase of the contact areas between the metallic particles [112,113]. When improved adhesion is required, a priming treatment can be applied to plasma preconditioned polymeric substrates [114].
Normally, mono- or di-functional monomers are used to adjust the resultant viscosity and surface tension of the formulated ink because they are more fluid, being this especially important in inkjet printing formulations where the use of highly viscous oligomers is restricted [115]. Frequently, most formulations contain a complex mixture of several oligomers and monomers that will be chosen considering the end-use and specific performance required for the printed ink (Fig. 7a).

Unsaturated monomers/oligomers undergo radical chain polymerization initiated by reactive species $\left(R^{*}\right)$ produced from an initiator compound (I). Following, the reactive species, which may be a free radical, cation, or anion, adds to a monomer/oligomer molecule by opening the $\pi$-bond to form a new radical, cation, or anion center. The process is repeated as many more unsaturated monomer/oligomer molecules are successively added to continuously propagate the reactive center (Fig. 7b). Polymer growth is terminated at some point by destruction of the reactive center by an appropriate reaction depending on the type of reactive center and the particular reaction conditions [116].

Most monomers/oligomers require some kind of initiator to start radical chain polymerization during ink curing. A large number of free radical initiators are available, and may be classified into four major types: peroxide and hydroperoxides, azo compounds, redox initiators, and certain compounds that form radicals under the influence of light (photoinitiators) [117]. In order to generate the reactive species, initiators require energy and mainly two types of processes have been used: (i) the action of heat (thermal curing), and (ii) the action of UV-light (UV curing). For thermal curing, peroxides have been widely used as initiators [108], although they present serious drawbacks such as their extreme exothermic reactivity that engenders risks of explosion if they are stored under unsuitable conditions (high temperature); this confers a poor thermal stability to peroxide-containing formulations which tend to gel prematurely [118]. For this reason, non-peroxide thermal radical initiators are preferred in conductive ink compositions [119].

Thermal curing has been widely used in printed electronics, but it always needs high temperature and long curing times that are not suitable for large scale production and temperature-sensitive substrates [120,121]. Instead, UV curing offers faster curing speed and has the advantages of high efficiency, low energy consumption and little environmental pollution [122]. On the other hand, as conductive fillers are not transparent and the color of the conductive system is mostly deeply gray, UV light can hardly reach the bottom of the printed pattern meaning that potential adhesion problems 


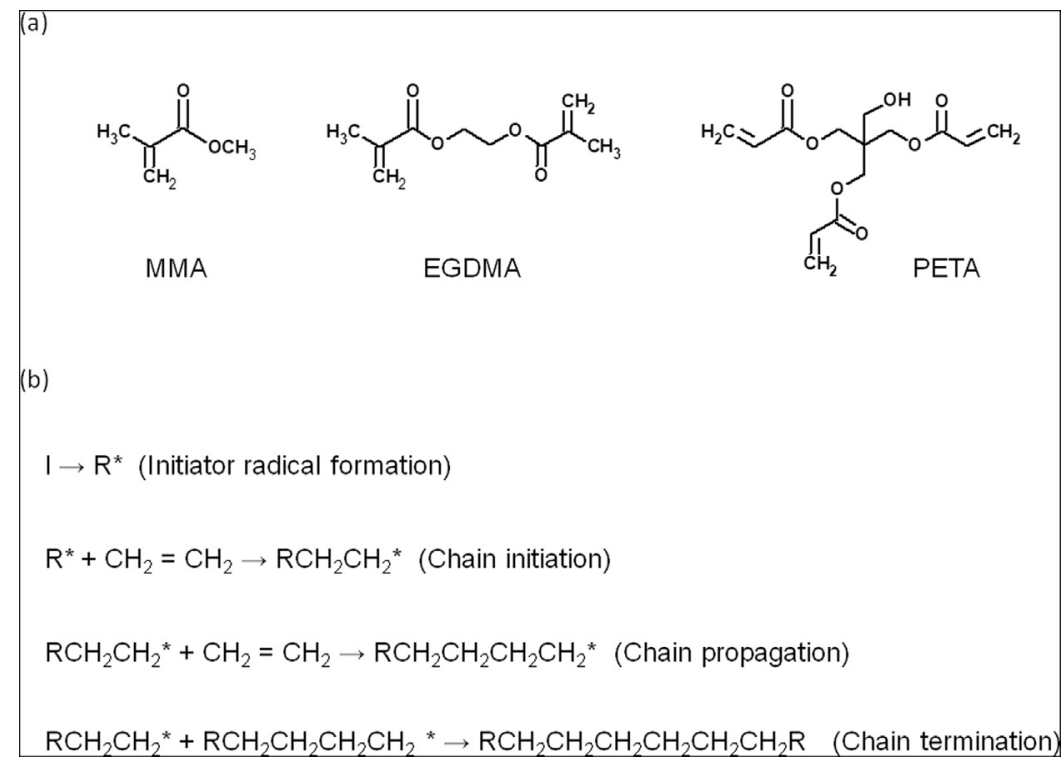

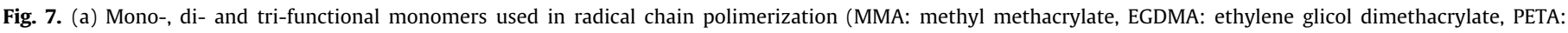
pentaerythritol triacrylate). (b) Schematic representation of radical chain polymerization.

may occur and non-uniform curing of large 3D surfaces happens [120]. As a solution, UV-thermal dual-curing technology has been presented to overcome curing defects into opaque systems, complex shapes, large thickness and colored films [123].

For UV-curing or dual-curing, the use of photoinitiators is mandatory to produce the free radicals that initiate the polymerization reaction. They can be of two types: type I undergo a unimolecular bond cleavage upon irradiation to yield free radicals, and type II undergo a bimolecular reaction where the excited state of the photo-initiator (acting as a photosensitizer) interacts with a second molecule (a co-initiator) to generate free radicals. Most UV-curable inks will contain several photo-initiators to ensure optimum cure [111].

In addition, electron beam (EB) has been used as another source of energy for curing processes in printed electronics [124-126]. In this case, the smallest unit of energy is the electron that is much more energetic $(70,000 \mathrm{eV})$ than the photon $(3.5 \mathrm{eV})$ in UV curing. Taking into account that the curing reactions initiate with the breaking of a double bond, whose typical energy is on the order of $5 \mathrm{eV}$, UV photons have less energy than the bond energy and cannot initiate curing on their own, and therefore, a photo-initiator is needed. In contrast, the energy of the electrons in EB curing easily exceeds the bond energy of the curable materials; thus curing initiation will occur without the need of an added photo-initiator. In terms of energy penetration, EB is much more effective than UV light and electrons are considered as "color blind" which means that curing is not affected by pigments and opaque substrates. Therefore, EB is ideal for curing high-opacity metallic inks [127].

Frequently, polymerizable formulations have been used to develop electrically conductive adhesives (ECA) in order to replace toxic $\mathrm{Sn} / \mathrm{Pb}$ solders in electronic devices fabricated by surface mount technology (SMT) [113]. In this type of applications, electrically conductive pastes are printed by techniques, such as screen-printing, which allow less-demanding rheological properties (ink viscosity and surface tension) and the use of larger metallic particles. In this sense, polymerizable pastes usually contain microsized metal particles that have a stronger oxidation resistance [128] and form electrically conductive paths by particle-to-particle contact and percolation phenomena [129], not existing a real sintering between metal microparticles. Nevertheless, Cui et al. presented well sintered structures in a silver micro-flakes based ECA by using ultra-fast photonic curing [31] (Fig. 8). In that work, electrical conductivity was improved by using small silver micro-flakes in combination with larger flakes to fill into the interspaces and holes, multiplying in such way the contact points and increasing the contact areas. Similar approaches have been presented by other authors using high-aspect-ratio nanobelts [130] or metal nanoparticles [131] to enhance the packing efficiency and thus decreasing the resistivity of such formulated ECA.

In addition, reactive or MOD polymerizable inks were developed, in which the nanoparticle formation and the cross-linking processes can be accomplished in one step by simply irradiating the appropriate formulations [132-134]. Within this strategy, Cook et al. [135] presented one mechanism where photoinduced reduction of $\mathrm{Ag}^{+}$ions and cationic polymerization of a divinyl monomer occur simultaneously (Fig. 9). In a similar approach, Chiolerio et al. [136] presented one formulation including water in order to improve ink viscosity for optimal inkjet printing processability.

More recently, polymerizable oil-in-water emulsion inks have been presented by Magdassi et al. In these inks, the oil phase contains polymerizable water-insoluble monomers that are going to form a 3D structure by UV curing, and the aqueous phase may contain a dispersion of conductive nanoparticles that imparts ink functionality [137]. In a different approach, conductive solution may be embedded in a second step after printing the 3D porous structure [138] (Fig. 10). In both cases, low-temperature chemical sintering was carried out by dipping the printed structure into $\mathrm{NaCl}$ solution or by exposing it to $\mathrm{HCl}$ vapors.

\subsection{Additives}

Additives, although are minor constituents (typically, $<5 \%$ by weight), greatly influence the overall performance of the ink. They can be used to enhance several ink properties like its rheology, pigment wetting, surface tension, adhesion to substrate, antifoaming, etc. Their cost is quite high, but their use is justified because small quantities of additives can really improve the quality of the ink.

Surfactants are usually used to adjust the surface tension of the formulated inks. This is especially important in water-based inks because water has a high surface tension $(72 \mathrm{mM} / \mathrm{m})$, most of the times higher than that of typical organic solvents $(\approx 20 \mathrm{mN} / \mathrm{m})$ and polymeric substrates, like polyethylene and polypropylene 


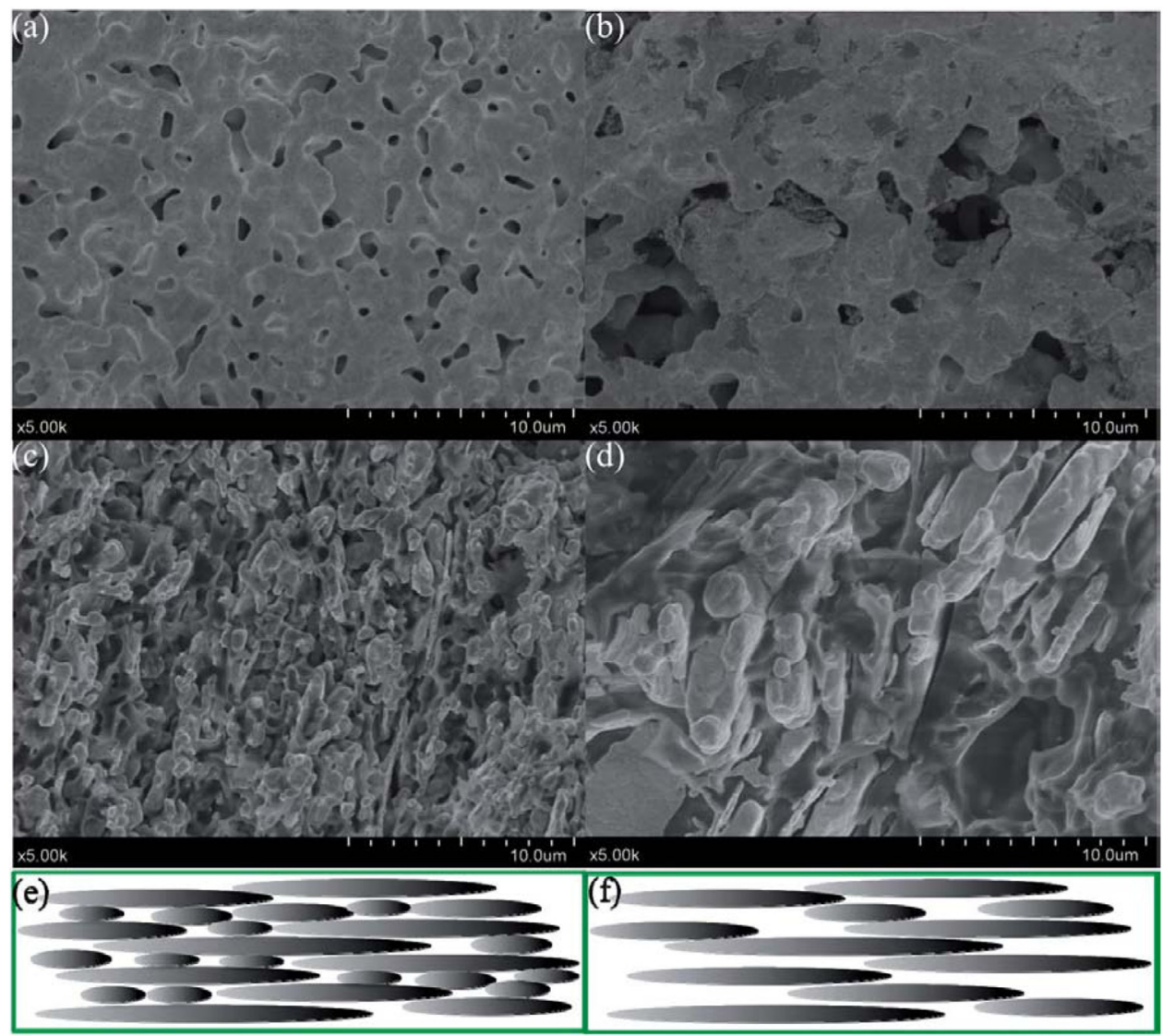

Fig. 8. Photonic curing of two silver-based ECA: (a) $90 \%$ silver flakes (2-15 $\mu \mathrm{m}$ ) and 500 light pulses; (b) $90 \%$ silver flakes (6-12 $\mu \mathrm{m}$ ) and 500 light pulses; (c) $90 \%$ silver flakes $(2-15 \mu \mathrm{m})$ and 100 light pulses; (d) 90\% silver flakes (6-12 $\mu \mathrm{m})$ and 100 light pulses; (e) and (f) are the schematic representations of possible arrangement models and packaging efficiency in both ECA.

Reproduced with permission from [31]. Copyright @ 2014, Royal Society of Chemistry.<smiles>Cc1cc(C)c(C(=O)OP(=O)(c2ccc(Br)cc2)c2c(C)cc(C)cc2C)c(C)c1</smiles><smiles>Cc1cc(C)c(C(=O)P(C)(=O)c2ccccc2)c(C)c1</smiles><smiles>CC(=O)c1c(C)cc(C)cc1C</smiles>

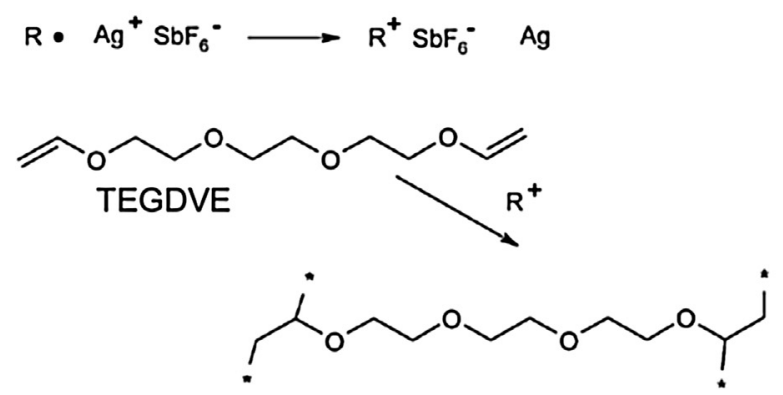

Fig. 9. Photolysis of the free radical photoinitiator BAPO (bis(2,4,6-trimethylbenzoyl)phenylphosphine oxide) and mechanism of photoinduced reduction of $\mathrm{Ag}^{+}$ions, besides cationic polymerization of TEGDVE (triethylene glicol divinyl ether) monomer.

Adapted with permission from [135]. Copyright @ 2011, American Chemical Society.

$(<32 \mathrm{mN} / \mathrm{m})$. Therefore, in order to have good printability conditions and best adhesion properties, surface tension of the ink should be adjusted to be lower than the surface free energy of the polymeric substrate. Surfactants are characterized by their hydrophile-lipophile balance (HLB), which is the ratio between the hydrophilic to lipophilic groups in the molecule. This factor is very useful and should be taken into account in order to select the proper surfactants for a certain mixture of solvents. There are many hundreds of surfactants available, including anionic, cationic, non-ionic and amphoteric forms. 


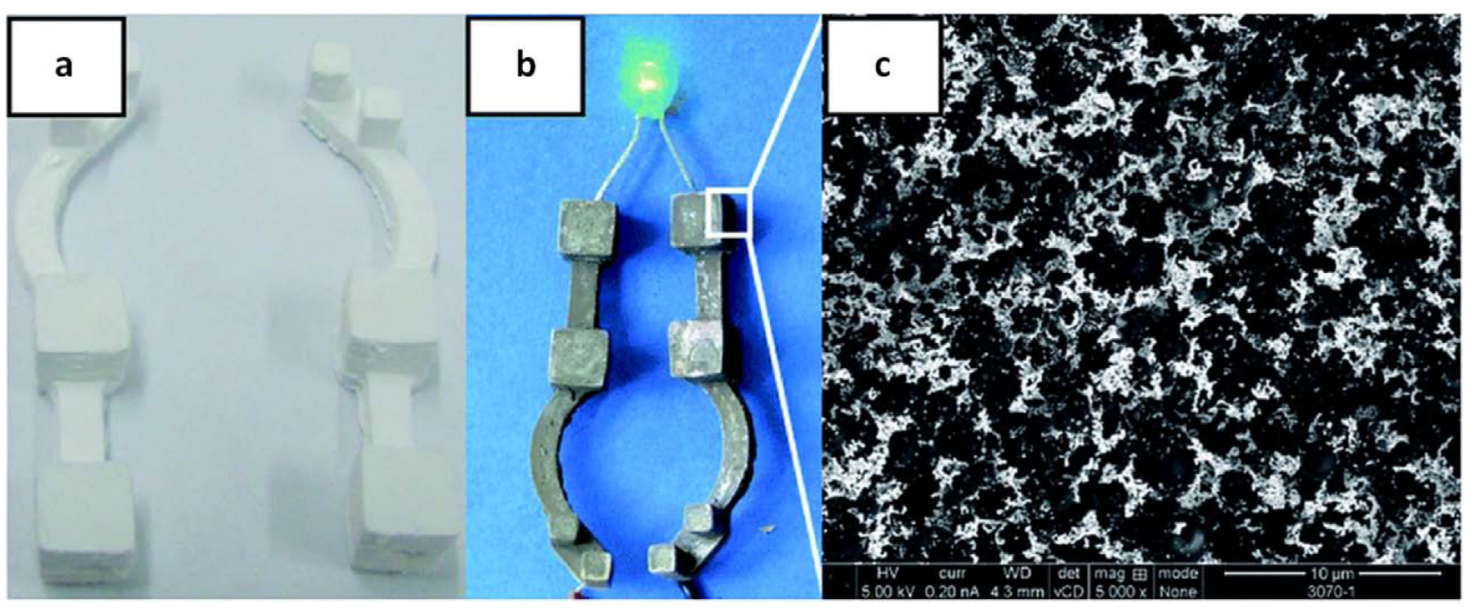

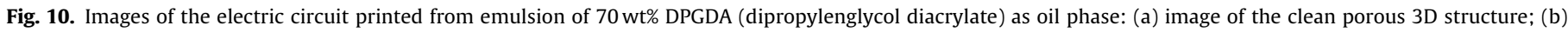

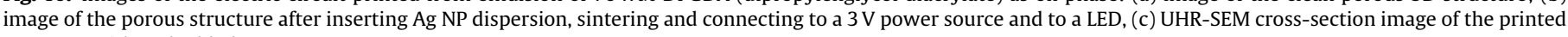
structure with embedded Ag NP.

Reproduced with permission from [138]. Copyright @ 2015 , Royal Society of Chemistry.

Sometimes surfactants produce undesirable effects, like bubbles stabilization, thus antifoaming agents or defoamers are added in order to prevent excessive bubbles forming. Mostly, they are silicone oils with polydimethyl siloxane as an active agent [139].

In general, polymers and solvents determine the rheological behavior of the formulated inks. However, rheology modifiers or thickeners could be added to control ink flow, temperature stability, ink penetration and settling of pigments or fillers that should be prevented during ink storage.

Plasticizers can block active centers of polymers to avoid crosslinking and so improve ink flexibility, and better adhesion to problematic flexible substrates [25].

In radiation-curing inks, photo-initiators can be considered as additives because they are added in very low concentrations $0.01-15.0 \%$, and as above mentioned; they are responsible for starting free-radical reactions. Additionally, inhibitors may be also required in this kind of inks to prevent premature reaction and spontaneous free-radical polymerization [140].

Other specific additives are: radical scavengers, added to protect ink from oxidation and weathering [141]; anti-skinning agents, to prevent skin formation in the ink surface; biocides and fungicides, to inhibit the growth of potential microorganisms, mainly in water-based inks, although this kind of additives may not be required in solid metal-based inks due to antimicrobial activity of metal nanofillers [142]; and other performance additives, like ionic liquids that are prospected to be used as an alternative to conventional solvents due to their nil significant vapor pressure that could reduce the emission of VOC in the printing processes [143].

\section{Concluding remarks}

Printed Electronics, PE, is an expanding market that promotes the commercialization of numerous metal-based inks formulations all over the world. Initially, many companies focused on the production of screen-printing pastes but later on moved to nanoparticles-based formulations. This happened mainly when non-contact techniques, such as inkjet printing, were implemented in the PE industry. Normally, nanoparticles-based inks provide a better resolution and control of the film thickness. However, the large-scale production of metal nanoparticles is still challenging mostly because they easily undergo oxidation, being more critical than in micron-size scale. For this reason, different antioxidation mechanisms are implemented in order to obtain feasible formulations with low-cost metals and proper long-term stability. More recently, reactive inkjet printing has emerged as a smart free-particle strategy, very suitable to solve clogging problems in inkjet printing heads. In the inkjet formulations, conductive fillers are produced in situ in the core of the printed patterns from different metal precursors. However, additional effort is necessary so as to improve the resultant conductivity of such printed patterns.

In addition, post-printing treatments have enormous influence in the performance of printed inks. They include metals sintering, solvents drying and polymers curing. Concerning the sintering processes, traditional thermal sintering is frequently replaced by alternative sintering techniques, e.g., photonic, microwave, plasma, electrical, chemically triggered room temperature coalescence. These techniques are more advisable for temperature-sensitive polymeric substrates and may reduce the oxidation of the metal fillers.

In solvent-based formulations, the current trend is directed to the use of environment-friendly solvents, typically water and ionic liquids that, due to their low vapor pressure, are considered as future alternative to conventional solvents in ink formulations.

Energy-curable formulations are considered a solution to solvent-based inks although, in general, they require an extra postprinting step to finalize ink curing. Traditionally, thermal curing is widely used in PE, however currently it is being replaced by more efficient curing processes, like UV and EB curing. These processes do not require such long curing times and are more suitable for mass-production. Frequently, they need the use of photoinitiators to induce radical chain polymerization that may promote the reduction of metallic ions, as well.

Solid metal-based inks have been used in diverse applications in the PE industry. For instance, they have been used to print radio frequency identification (RFID) tags, thin-film transistors (TFT), light-emitting diodes (LED), transparent conductive electrodes (TCE) and organic solar cells (OSC) [34], among others. Electronic textiles and 3D printed electronics are emerging fields that explain novel PE applications reaching pilot production and manufacturing stages.

Nowadays, solid metal-based formulations are used when good adhesion and abrasion durability are required. There are indications that the widely used silver-based inks will be gradually replaced by compositions containing cheaper metals like copper, aluminum, or nickel. Most probably, the research and development in the area of printed electronics will continue to be focused on the production 
of low-cost oxidation-free solid metal formulations with improved long-term stability [89].

\section{Conflicts of interest}

None.

\section{Acknowledgements}

The authors gratefully acknowledge the financial support of the NORTE 2020 project TSSIPRO (Technologies for Sustainable and Smart Innovative Products, NORTE-01-0145-FEDER-000015) and the COMPETE project iFACTORY: Novas Capacidades de Industrialização (POCI-01-0247-FEDER-002814).

\section{References}

[1] IDTechEx; https://www.idtechex.com/research/articles/printed-electronicskey-trends-00015712.asp (visited 05/02/2019).

[2] K. Gilleo, Polymer Thick Film: Today's Emerging Technology for a Clean Environment Tomorrow, Springer, 1995

[3] W. Wu, Inorganic nanomaterials for printed electronics: a review, Nanoscale 9 (2017) 7342-7372, http://dx.doi.org/10.1039/C7NR01604B.

[4] Y.I. Lee, Y.H. Choa, Adhesion enhancement of ink-jet printed conductive copper patterns on a flexible substrate, J. Mater. Chem. 22 (2012) 12517-12522, http://dx.doi.org/10.1039/c2jm31381b.

[5] S. Khan, L. Lorenzelli, R.S. Dahiya, Technologies for printing sensors and electronics over large flexible substrates: a review, IEEE Sens. J. 15 (2014) 3164-3185, http://dx.doi.org/10.1109/JSEN.2014.2375203.

[6] J. Izdebska, S. Thomas, Printing on Polymers: Fundamentals and Applications, Elsevier Inc., 2016.

[7] M. Li, Y.T. Li, D.W. Li, Y.T. Long, Recent developments and applications of screen-printed electrodes in environmental assays-a review, Anal. Chim. Acta 734 (2012) 31-44, http://dx.doi.org/10.1016/J.ACA.2012.05.018.

[8] S. Magdassi, A. Kamyshny, Nanomaterials for 2D and 3D Printing, Wiley-VCH Verlag GmbH \& Co. KGaA, 2017, http://dx.doi.org/10.1002/9783527685790.

[9] Z.P. Yin, Y.A. Huang, N.B. Bu, X.M. Wang, Y.L. Xiong, Inkjet printing for flexible electronics: materials, processes and equipments, Chin. Sci. Bull. 55 (2010) 3383-3407, http://dx.doi.org/10.1007/s11434-010-3251-y.

[10] R. Søndergaard, M. Hösel, D. Angmo, T.T. Larsen-Olsen, F.C. Krebs, Roll-to-roll fabrication of polymer solar cells, Mater. Today 15 (2012) 36-49, http://dx.doi.org/10.1016/S1369-7021(12)70019-6.

[11] A. Kamyshny, J. Steinke, S. Magdassi, Metal-based inkjet inks for printed electronics, Open Appl. Phys. J. 4 (2011) 19-36, http://dx.doi.org/10.2174/ 1874183501104010019.

[12] K. Rajan, I. Roppolo, A. Chiappone, S. Bocchini, D. Perrone, A. Chiolerio, Silver nanoparticle ink technology: state of the art, Nanotechnol. Sci. Appl. 9 (2016) 1-13, http://dx.doi.org/10.2147/NSA.S68080.

[13] V.K. Abhinav, V.K.R. Rao, P.S. Karthik, S.P. Singh, Copper conductive inks: synthesis and utilization in flexible electronics, RSC Adv. 5 (2015) 63985-64030, http://dx.doi.org/10.1039/C5RA08205F.

[14] W. Cui, W. Lu, Y. Zhang, G. Lin, T. Wei, L. Jiang, Gold nanoparticle ink suitable for electric-conductive pattern fabrication using in ink-jet printing technology, Colloids Surf. A: Physicochem. Eng. Asp. 358 (2010) 35-41, http://dx.doi.org/10.1016/j.colsurfa.2010.01.023.

[15] J.H. Kim, S. Lee, M. Wajahat, H. Jeong, W.S. Chang, H.J. Jeong, J.R. Yang, J.T. Kim, S.K. Seol, Three-dimensional printing of highly conductive carbon nanotube microarchitectures with fluid ink, ACS Nano 10 (2016) 8879-8887, http://dx.doi.org/10.1021/acsnano.6b04771.

[16] L. Huang, Y. Huang, J. Liang, X. Wan, Y. Chen, Graphene-based conducting inks for direct inkjet printing of flexible conductive patterns and their applications in electric circuits and chemical sensors, Nano Res. 4 (2011) 675-684, http://dx.doi.org/10.1007/s12274-011-0123-z.

[17] Transparent ORGACON Transparent conductive inkjet ink: IJ Orgacon inkjet inks are highly transparent conductive inks based on conductive polymer PEDOT/PSS, Mater. Data Sheet. (2013). https://www.agfa.com/sp/global/en/ binaries/IJ1005-2013v1.1_tcm611-86919.pdf.

[18] L. Wang, J. Liu, Liquid metal inks for flexible electronics and 3D printing: a review, Adv. Manuf. 2B (2014), http://dx.doi.org/10.1115/IMECE201437993, V02BT02A044.

[19] X. Wang, J. Liu, Recent advancements in liquid metal flexible printed electronics: properties, technologies, and applications, Micromachines 7 (2016) 206, http://dx.doi.org/10.3390/mi7120206.

[20] L. Tang, S. Cheng, L. Zhang, H. Mi, L. Mou, S. Yang, Z. Huang, X. Shi, X. Jiang, Printable metal-polymer conductors for highly stretchable bio-devices, IScience 4 (2018) 302-311, http://dx.doi.org/10.1016/j.isci.2018.05.013.

[21] M.G. Mohammed, R. Kramer, All-printed flexible and stretchable electronics, Adv. Mater. 29 (2017), http://dx.doi.org/10.1002/adma.201604965.

[22] M.D. Dickey, R.C. Chiechi, R.J. Larsen, E.A. Weiss, D.A. Weitz, G.M. Whitesides, Eutectic gallium-indium (EGaIn): a liquid metal alloy for the formation of stable structures in microchannels at room temperature, Adv. Funct. Mater. 18 (2008) 1097-1104, http://dx.doi.org/10.1002/adfm.200701216.

[23] M.M. Nir, D. Zamir, I. Haymov, L. Ben-Asher, O. Cohen, B. Faulkner, F. de la Vega, Electrically Conductive Inks for Inkjet Printing, Chem. Inkjet Inks, World Scientific, 2011, pp. 225-254, http://dx.doi.org/10.1142/ 9789812818225_0012.

[24] P.T. Bishop, L.J. Ashfield, A. Berzins, A. Boardman, V. Buche, J. Cookson, R.J. Gordon, C. Salcianu, P.A. Sutton, Printed gold for electronic applications, Gold Bull. 43 (2010) 181-188, http://dx.doi.org/10.1007/BF03214985.

[25] A. Pekarovicova, V. Husovska, Printing ink formulations, Print. Polym. (2016) 41-55, http://dx.doi.org/10.1016/B978-0-323-37468-2.00003-8, Elsevier.

[26] J. Rockenberger, F. Zürcher, W. Guo, Aluminum inks and methods of making the same, methods for depositing aluminum inks, and films formed by printing and/or depositing an aluminum ink (US20100022078A1), 2010.

[27] V.V. Lockett, A.E. Hartman, J.G. Gustafson, M.D. Lowenthal, W.J. Ray, Nickel inks and oxidation resistant and conductive coatings (US20140183421A1), 2014.

[28] R. Strumpler, J. Glatz-Reichenbach, Conducting polymer composites, J. Electroceram. 3 (1999) 329-346, http://dx.doi.org/10.1023/ A:1009909812823.

[29] A. Kamyshny, S. Magdassi, Conductive nanomaterials for printed electronics, Small 10 (2014) 3515-3535, http://dx.doi.org/10.1002/smll.201303000.

[30] W.J. Hyun, S. Lim, B.Y. Ahn, J.A. Lewis, C.D. Frisbie, L.F. Francis, Screen printing of highly loaded silver inks on plastic substrates using silicon stencils, ACS Appl. Mater. Interfaces 7 (2015) 12619-12624, http://dx.doi. org/10.1021/acsami.5b02487.

[31] H.-W. Cui, J.-T. Jiu, S. Nagao, T. Sugahara, K. Suganuma, H. Uchida, K.A. Schroder, Ultra-fast photonic curing of electrically conductive adhesives fabricated from vinyl ester resin and silver micro-flakes for printed electronics, RSC Adv. 4 (2014) 15914-15922, http://dx.doi.org/10.1039/ C4RA00292J.

[32] X. Yang, W. He, S. Wang, G. Zhou, Y. Tang, J. Yang, Effect of the different shapes of silver particles in conductive ink on electrical performance and microstructure of the conductive tracks, J. Mater. Sci. Mater. Electron. 23 (2012) 1980-1986, http://dx.doi.org/10.1007/s10854-012-0691-z.

[33] L.V.M. Antony, R.G. Reddy, Processes for production of high-purity metal powders, JOM 55 (2003) 14-18, http://dx.doi.org/10.1007/s11837-0030153-4.

[34] A. Kamyshny, S. Magdassi, Metallic nanoinks for inkjet printing of conductive 2D and 3D structures, in: Nanomater. 2D 3D Print, Wiley-VCH Verlag GmbH \& Co. KGaA, 2017, pp. 119-160, http://dx.doi.org/10.1002/ 9783527685790.ch7.

[35] R. Streubel, S. Barcikowski, B. Gökce, Continuous multigram nanoparticle synthesis by high-power, high-repetition-rate ultrafast laser ablation in liquids, Opt. Lett. 41 (2016) 1486-1489, http://dx.doi.org/10.1364/OL.41. 001486.

[36] H. Bönnemann, R.M. Richards, Nanoscopic metal particles - synthetic methods and potential applications, Eur. J. Inorg. Chem. (2001) 2455-2480, https://doi.org/10.1002/1099-0682(200109)2001:10\%3C2455::AIDEJIC2455\%3E3.0.CO;2-Z.

[37] J. Dupont, G.S. Fonseca, A.P. Umpierre, P.F.P. Fichtner, S.R. Teixeira, Transition-metal nanoparticles in imidazolium ionic liquids: Recycable catalysts for biphasic hydrogenation reactions, J. Am. Chem. Soc. 124 (2002) 4228-4229, http://dx.doi.org/10.1021/ja025818u.

[38] J. Cheon, J. Lee, J. Kim, Inkjet printing using copper nanoparticles synthesized by electrolysis, Thin Solid Films 520 (2012) 2639-2643, http:// dx.doi.org/10.1016/j.tsf.2011.11.021.

[39] B.-H. Ryu, Y. Choi, H.-S. Park, J.-H. Byun, K. Kong, J.-O. Lee, H. Chang, Synthesis of highly concentrated silver nanosol and its application to inkjet printing, Colloids Surf. A: Physicochem. Eng. Asp. 270-271 (2005) 345-351, http://dx.doi.org/10.1016/j.colsurfa.2005.09.005.

[40] S. Magdassi, A. Bassa, Y. Vinetsky, A. Kamyshny, Silver nanoparticles as pigments for water-based ink-jet inks, Chem. Mater. 15 (2003) 2208-2217, http://dx.doi.org/10.1021/cm021804b.

[41] X. Sun, S. Dong, E. Wang, One-step synthesis and characterization of polyelectrolyte-protected gold nanoparticles through a thermal process, Polymer (Guildf.) 45 (2004) 2181-2184, http://dx.doi.org/10.1016/j. polymer.2004.01.010.

[42] K. Woo, C. Bae, Y. Jeong, D. Kim, J. Moon, Inkjet-printed Cu source/drain electrodes for solution-deposited thin film transistors, J. Mater. Chem. 20 (2010) 3877-3882, http://dx.doi.org/10.1039/C000162G.

[43] S. Jeong, S.H. Lee, Y. Jo, S.S. Lee, Y.-H. Seo, B.W. Ahn, G. Kim, G.-E. Jang, J.U. Park, B.-H. Ryu, Y. Choi, Air-stable, surface-oxide free $\mathrm{Cu}$ nanoparticles for highly conductive $\mathrm{Cu}$ ink and their application to printed graphene transistors, J. Mater. Chem. C 1 (2013) 2704-2710, http://dx.doi.org/10. 1039/C3TC00904A.

[44] S. Jeong, H.C. Song, W.W. Lee, S.S. Lee, Y. Choi, W. Son, E.D. Kim, C.H. Paik, S.H. Oh, B.H. Ryu, Stable aqueous based Cu nanoparticle ink for printing well-defined highly conductive features on a plastic substrate, Langmuir 27 (2011) 3144-3149, http://dx.doi.org/10.1021/la104136w.

[45] C.Y. Tsai, W.C. Chang, G.L. Chen, C.H. Chung, J.X. Liang, W.Y. Ma, T.N. Yang, A Study of the preparation and properties of antioxidative copper inks with high electrical conductivity, Nanoscale Res. Lett. 10 (2015) 357, http://dx. doi.org/10.1186/s11671-015-1069-y. 
[46] X. Song, S. Sun, W. Zhang, Z. Yin, A method for the synthesis of spherical copper nanoparticles in the organic phase, J. Colloid Interface Sci. 273 (2004) 463-469, http://dx.doi.org/10.1016/j.jcis.2004.01.019.

[47] J. Kwon, S. Park, M. Haque, Y. Kim, C. Lee, Study of sintering behavior of vapor forms of 1-octanethiol coated copper nanoparticles for application to ink-jet printing technology, J. Nanosci. Nanotechnol. 12 (2012) 3434-3437.

[48] S.H. Park, H.S. Kim, Flash light sintering of nickel nanoparticles for printed electronics, Thin Solid Films 550 (2014) 575-581, http://dx.doi.org/10.1016/ j.tsf.2013.11.075.

[49] N.R. Kim, Y.J. Lee, C. Lee, J. Koo, H.M. Lee, Surface modification of oleylamine-capped $\mathrm{Ag}$-Cu nanoparticles to fabricate low-temperature-sinterable Ag-Cu nanoink, Nanotechnology 27 (2016) 345706, http://stacks.iop.org/0957-4484/27/i=34/a=345706.

[50] M. Grouchko, A. Kamyshny, S. Magdassi, Formation of air-stable copper-silver core-shell nanoparticles for inkjet printing, J. Mater. Chem. 19 (2009) 3057-3062, http://dx.doi.org/10.1039/B821327E.

[51] S. Magdassi, M. Grouchko, A. Kamyshny, Copper nanoparticles for printed electronics: routes towards achieving oxidation stability, Materials (Basel) 3 (2010) 4626-4638, http://dx.doi.org/10.3390/ma3094626.

[52] K. Kim, S. Il Ahn, K.C. Choi, Direct fabrication of copper patterns by reactive inkjet printing, Curr. Appl. Phys. 13 (2013) 1870-1873, http://dx.doi.org/10. 1016/j.cap.2013.07.021.

[53] W. Yang, C. Wang, V. Arrighi, An organic silver complex conductive ink using both decomposition and self-reduction mechanisms in film formation, J. Mater. Sci. Mater. Electron. 29 (2018) 2771-2783, http://dx.doi.org/10.1007/ s10854-017-8205-7.

[54] K.R. Zope, D. Cormier, S.A. Williams, Reactive silver oxalate ink composition with enhanced curing conditions for flexible substrates, ACS Appl. Mater. Interfaces 10 (2018) 3830-3837, http://dx.doi.org/10.1021/acsami.7b19161.

[55] S.B. Walker, J.A. Lewis, Reactive silver inks for patterning high-conductivity features at mild temperatures, J. Am. Chem. Soc. 134 (2012) 1419-1421, http://dx.doi.org/10.1021/ja209267c.

[56] J.J.P. Valeton, K. Hermans, C.W.M. Bastiaansen, D.J. Broer, J. Perelaer, U.S Schubert, G.P. Crawford, P.J. Smith, Room temperature preparation of conductive silver features using spin-coating and inkjet printing, J. Mater. Chem. 20 (2010) 543-546, http://dx.doi.org/10.1039/b917266a.

[57] J.J. Chen, J. Zhang, Y. Wang, Y.L. Guo, Z.S. Feng, A particle-free silver precursor ink useful for inkjet printing to fabricate highly conductive patterns, J. Mater. Chem. C. 4 (2016) 10494-10499, http://dx.doi.org/10. 1039/c6tc03719d.

[58] Z. Cai, X. Zeng, J. Liu, Laser direct writing of conductive silver film on polyimide surface from decomposition of organometallic ink, J. Electron. Mater. 40 (2011) 301-305, http://dx.doi.org/10.1007/s11664-010-1418-7.

[59] Y. Dong, Z. Lin, X. Li, Q. Zhu, J.G. Li, X. Sun, A low temperature and air-sinterable copper-diamine complex-based metal organic decomposition ink for printed electronics, J. Mater. Chem. C 6 (2018) 6406-6415, http://dx. doi.org/10.1039/c8tc01849a.

[60] N. Komoda, M. Nogi, K. Suganuma, K. Otsuka, Highly sensitive antenna using inkjet overprinting with particle-free conductive inks, ACS Appl. Mater. Interfaces 4 (2012) 5732-5736, http://dx.doi.org/10.1021/am301747p.

[61] S.F. Jahn, T. Blaudeck, R.R. Baumann, A. Jakob, P. Ecorchard, T. Rüffer, H. Lang, P. Schmidt, Inkjet printing of conductive silver patterns by using the first aqueous particle-free MOD ink without additional stabilizing ligands, Chem. Mater. 22 (2010) 3067-3071, http://dx.doi.org/10.1021/cm9036428.

[62] P.J. Smith, A. Morrin, Reactive inkjet printing - an introduction, in: React. Inkjet Print. A Chem. Synth. Tool, The Royal Society of Chemistry, 2018, pp. 1-11, http://dx.doi.org/10.1039/9781788010511-00001.

[63] D. Li, D. Sutton, A. Burgess, D. Graham, P.D. Calvert, Conductive copper and nickel lines via reactive inkjet printing, J. Mater. Chem. 19 (2009) 3719-3724, http://dx.doi.org/10.1039/B820459D.

[64] M. Abulikemu, E.H. Da'as, H. Haverinen, D. Cha, M.A. Malik, G.E. Jabbour, In situ synthesis of self-assembled gold nanoparticles on glass or silicon substrates through reactive inkjet printing, Angew. Chem. 126 (2014) 430-433, http://dx.doi.org/10.1002/ange.201308429.

[65] Y.S. Rosen, A. Yakushenko, A. Offenhäusser, S. Magdassi, Self-reducing copper precursor inks and photonic additive yield conductive patterns under intense pulsed light, ACS Omega 2 (2017) 573-581, http://dx.doi.org/ 10.1021/acsomega.6b00478.

[66] W. Li, S. Cong, J. Jiu, S. Nagao, K. Suganuma, Self-reducible copper inks composed of copper-amino complexes and preset submicron copper seeds for thick conductive patterns on a flexible substrate, J. Mater. Chem. C 4 (2016) 8802-8809, http://dx.doi.org/10.1039/C6TC02914K.

[67] Y. Kawaguchi, Y. Hotta, H. Kawasaki, Cu-based composite inks of a self-reductive $\mathrm{Cu}$ complex with $\mathrm{Cu}$ flakes for the production of conductive Cu films on cellulose paper, Mater. Chem. Phys. 197 (2017) 87-93, http://dx doi.org/10.1016/j.matchemphys.2017.05.017.

[68] B.J. Perelaer, A.W.M. de Laat, C.E. Hendriks, U.S. Schubert, Inkjet-printed silver tracks: low temperature curing and thermal stability investigation, J. Mater. Chem. 18 (2008) 3209-3215, http://dx.doi.org/10.1039/B720032C.

[69] J. Perelaer, C.E. Hendriks, A.W.M. de Laat, U.S. Schubert, One-step inkjet printing of conductive silver tracks on polymer substrates, Nanotechnology 20 (2009) 165303, http://stacks.iop.org/0957-4484/20/i=16/a=165303.

[70] S. Wünscher, R. Abbel, J. Perelaer, U.S. Schubert, Progress of alternative sintering approaches of inkjet-printed metal inks and their application for manufacturing of flexible electronic devices, J. Mater. Chem. C 2 (2014) 10232-10261, http://dx.doi.org/10.1039/C4TC01820F.
[71] L. Liu, X. Wan, L. Sun, S. Yang, Z. Dai, Q. Tian, M. Lei, X. Xiao, C. Jiang, W. Wu, Anion-mediated synthesis of monodisperse silver nanoparticles useful for screen printing of high-conductivity patterns on flexible substrates for printed electronics, RSC Adv. 5 (2015) 9783-9791, http://dx.doi.org/10. 1039/C4RA13641A.

[72] T. Yonezawa, H. Tsukamoto, Y. Yong, M.T. Nguyen, M. Matsubara, Low temperature sintering process of copper fine particles under nitrogen gas flow with $\mathrm{Cu} 2+-$ alkanolamine metallacycle compounds for electrically conductive layer formation, RSC Adv. 6 (2016) 12048-12052, http://dx.doi org/10.1039/c5ra25058g.

[73] Y. Gao, H. Zhang, W. Li, J. Jiu, S. Nagao, T. Sugahara, K. Suganuma, Die bonding performance using bimodal Cu particle paste under different sintering atmospheres, J. Electron. Mater. 46 (2017) 4575-4581, http://dx. doi.org/10.1007/s11664-017-5464-2.

[74] J. Niittynen, R. Abbel, M. Mäntysalo, J. Perelaer, U.S. Schubert, D. Lupo, Alternative sintering methods compared to conventional thermal sintering for inkjet printed silver nanoparticle ink, Thin Solid Films 556 (2014) 452-459, http://dx.doi.org/10.1016/j.tsf.2014.02.001.

[75] I. Kim, K. Woo, Z. Zhong, E. Lee, D. Kang, S. Jeong, Y.-M. Choi, Y. Jang, S. Kwon, J. Moon, Selective light-induced patterning of carbon nanotube/silver nanoparticle composite to produce extremely flexible conductive electrodes, ACS Appl. Mater. Interfaces 9 (2017) 6163-6170, http://dx.doi. org/10.1021/acsami.6b14580.

[76] O. Abed, K. Ginsberg, J.P. Novak, Photosintering of micron-sized copper particles (US20150147486A1), 2015.

[77] D. Paeng, D. Lee, J. Yeo, J.-H. Yoo, F.I. Allen, E. Kim, H. So, H.K. Park, A.M. Minor, C.P. Grigoropoulos, Laser-induced reductive sintering of nickel oxide nanoparticles under ambient conditions, J. Phys. Chem. C 119 (2015) 6363-6372, http://dx.doi.org/10.1021/jp512776p.

[78] J.H. Park, S. Jeong, E.J. Lee, S.S. Lee, J.Y. Seok, M. Yang, Y. Choi, B. Kang, Transversally extended laser plasmonic welding for oxidation-free copper fabrication toward high-fidelity optoelectronics, Chem. Mater. 28 (2016) 4151-4159, http://dx.doi.org/10.1021/acs.chemmater.6b00013.

[79] J. Ryu, H.-S. Kim, H.T. Hahn, Reactive sintering of copper nanoparticles using intense pulsed light for printed electronics, J. Electron. Mater. 40 (2011) 42-50, http://dx.doi.org/10.1007/s11664-010-1384-0.

[80] F. Paglia, D. Vak, J. van Embden, A.S.R. Chesman, A. Martucci, J.J. Jasieniak, E. Della Gaspera, Photonic sintering of copper through the controlled reduction of printed $\mathrm{CuO}$ nanocrystals, ACS Appl. Mater. Interfaces 7 (2015) 25473-25478, http://dx.doi.org/10.1021/acsami.5b08430.

[81] M.L. Allen, M. Aronniemi, T. Mattila, A. Alastalo, K. Ojanperä, M. Suhonen, H. Seppä, Electrical sintering of nanoparticle structures, Nanotechnology 19 (2008) 175201, http://stacks.iop.org/0957-4484/19/i=17/a=175201.

[82] M.J. Coutts, M.B. Cortie, M.J. Ford, A.M. McDonagh, Rapid and controllable sintering of gold nanoparticle inks at room temperature using a chemical agent, J. Phys. Chem. C 113 (2009) 1325-1328, http://dx.doi.org/10.1021/ jp808927t.

[83] D. Wakuda, M. Hatamura, K. Suganuma, Novel method for room temperature sintering of Ag nanoparticle paste in air, Chem. Phys. Lett. 441 (2007) 305-308, http://dx.doi.org/10.1016/j.cplett.2007.05.033.

[84] S. Magdassi, M. Grouchko, O. Berezin, A. Kamyshny, Triggering the sintering of silver nanoparticles at room temperature, ACS Nano 4 (2010) 1943-1948, http://dx.doi.org/10.1021/nn901868t.

[85] M. Grouchko, A. Kamyshny, C.F. Mihailescu, D.F. Anghel, S. Magdassi, Conductive inks with a "built-in" mechanism that enables sintering at room temperature, ACS Nano 5 (2011) 3354-3359, http://dx.doi.org/10.1021/ nn2005848.

[86] M. Layani, S. Magdassi, Flexible transparent conductive coatings by combining self-assembly with sintering of silver nanoparticles performed at room temperature, J. Mater. Chem. 21 (2011) 15378-15382, http://dx.doi. org/10.1039/C1JM13174E.

[87] Z. Wang, W. Wang, Z. Jiang, D. Yu, Low temperature sintering nano-silver conductive ink printed on cotton fabric as printed electronics, Prog. Org. Coat. 101 (2016) 604-611, http://dx.doi.org/10.1016/j.porgcoat.2016.08. 019.

[88] M.S. Rager, T. Aytug, G.M. Veith, P. Joshi, Low-thermal-budget photonic processing of highly conductive $\mathrm{Cu}$ interconnects based on $\mathrm{CuO}$ nanoinks: Potential for flexible printed electronics, ACS Appl. Mater. Interfaces 8 (2016) 2441-2448, http://dx.doi.org/10.1021/acsami.5b12156.

[89] W. Li, L. Li, Y. Gao, D. Hu, C.F. Li, H. Zhang, J. Jiu, S. Nagao, K. Suganuma, Highly conductive copper films based on submicron copper particles/copper complex inks for printed electronics: microstructure, resistivity, oxidation resistance, and long-term stability, J. Alloys Compd. 732 (2018) 240-247, http://dx.doi.org/10.1016/j.jallcom.2017.10.193.

[90] A. Soleimani-Gorgani, Co-solvents roles in PEDOT:PSS ink-jet inks, Adv. Nat. Sci. Nanosci. Nanotechnol. 9 (2018) 25009, http://stacks.iop.org/2043-6262/ $9 / \mathrm{i}=2 / \mathrm{a}=025009$.

[91] J. Samuel, P. Edwards, Solvent-based inkjet inks, in: Chem. Inkjet Inks, 2009, pp. 141-159, http://dx.doi.org/10.1142/9789812818225_0008.

[92] Y. Li, D.M. Roundhill, X. Li, P.B. Laxton, H. Arimura, Z. Yaniv, Metallic ink (US 20090274833A1), 2009

[93] J. Heyen, M. Carmody, Performance of conductive copper paste using copper flake (US20140287158A1), 2014.

[94] J. Olkkonen, J. Leppaniemi, T. Mattila, K. Eiroma, Sintering of inkjet printed silver tracks with boiling salt water, J. Mater. Chem. C 2 (2014) 3577-3582, http://dx.doi.org/10.1039/C3TC32565B. 
[95] Y. Kim, B. Lee, S. Yang, I. Byun, I. Jeong, S.M. Cho, Use of copper ink for fabricating conductive electrodes and RFID antenna tags by screen printing, Curr. Appl. Phys. 12 (2012) 473-478, http://dx.doi.org/10.1016/j.cap.2011. 08.003.

[96] K. Wu, A. Henckens, Electrically conductive inks (US20160035910A1), 2016.

[97] S.H. Jeong, Y.M. Choi, B.H. Ryu, Y.H. Seo, S.H. Lee, Synthetic method of supressing metal nano-particle from having oxidized film and method of manufacturing conductive metal thin film via solution-processed (US20150053464A1), 2015.

[98] A. Kell, S. Lafreniere, C. Paquet, P. Malenfant, O. Mozenson, Molecular inks, WO2015192248A1, 2015

[99] Y. Gu, A. Wu, J.F. Federici, X. Zhang, Inkjet printable constantan ink for the fabrication of flexible and conductive film, Chem. Eng. J. 313 (2017) 27-36, http://dx.doi.org/10.1016/j.cej.2016.12.071.

[100] N.N. Jason, W. Shen, W. Cheng, Copper nanowires as conductive ink for low-cost draw-on electronics, ACS Appl. Mater. Interfaces 7 (2015) 16760-16766, http://dx.doi.org/10.1021/acsami.5b04522.

[101] S. Hemmatia, D.P. Barkeya, N. Guptaa, R. Banfieldb, Synthesis and characterization of silver nanowire suspensions for printable conductive media, ECS J. Solid State Sci. Technol. 4 (2015) P3075-P3079, http://dx.doi. org/10.1149/2.0121504jss.

[102] M.S. Mannoor, Z. Jiang, T. James, Y.L. Kong, K.A. Malatesta, W.O. Soboyejo, N. Verma, D.H. Gracias, M.C. McAlpine, 3D printed bionic ears, Nano Lett. 13 (2013) 2634-2639, http://dx.doi.org/10.1021/nl4007744.

[103] J. Kastner, T. Faury, H.M. Außerhuber, T. Obermüller, H. Leichtfried, M.J. Haslinger, E. Liftinger, J. Innerlohinger, I. Gnatiuk, D. Holzinger, T. Lederer, Silver-based reactive ink for inkjet-printing of conductive lines on textiles, Microelectron. Eng. 176 (2017) 84-88, http://dx.doi.org/10.1016/j.mee. 2017.02.004.

[104] R.D. Deegan, O. Bakajin, T.F. Dupont, G. Huber, S.R. Nagel, T.A. Witten, Capillary flow as the cause of ring stains from dried liquid drops, Nature 389 (1997) 827-829, http://dx.doi.org/10.1038/39827.

[105] M. Layani, R. Berman, S. Magdassi, Printing holes by a dewetting solution enables formation of a transparent conductive film, ACS Appl. Mater. Interfaces 6 (2014) 18668-18672, http://dx.doi.org/10.1021/am504106s.

[106] S.W. Kwok, K.H.H. Goh, Z.D. Tan, S.T.M. Tan, W.W. Tjiu, J.Y. Soh, Z.J.G. Ng, Y.Z. Chan, H.K. Hui, K.E.J. Goh, Electrically conductive filament for 3D-printed circuits and sensors, Appl. Mater. Today 9 (2017) 167-175, http://dx.doi.org/ 10.1016/j.apmt.2017.07.001.

[107] G.H. Hutchinson, Ink technology past, present and future, Surf. Coat. Int. B: Coat. Int. 85 (2002) 169-176, http://dx.doi.org/10.1007/BF02699505.

[108] H. Jiang, A.S. Shaikh, Electrically conductive polymeric compositions, contacts, assemblies, and methods (US20150107659A1), 2015.

[109] J.-H. Choi, S.-W. Lee, J.-H. Jeong, D.-G. Choi, J.-H. Lee, E.-S. Lee, Direct imprinted conductive patterns using nanosilver colloid-applied UV curable resist, Jpn. J. Appl. Phys. 48 (2009) 06FH02, http://stacks.iop.org/1347-4065/ $48 / \mathrm{i}=6 \mathrm{~S} / \mathrm{a}=06 \mathrm{FH} 02$.

[110] K.-C. Chiou, J.-R. Chen, H.-M. Chen, Conductive pastes (US20130146820A1), 2013

[111] S.E. Edison, Formulating UV Curable inkjet inks, in: Chem. Inkjet Inks, 2009, pp. 161-176, http://dx.doi.org/10.1142/9789812818225_0009.

[112] D. Lu, C.P. Wong, Effects of shrinkage on conductivity of isotropic conductive adhesives, Int. J. Adhes. Adhes. 20 (2000) 189-193, http://dx.doi.org/10. 1016/S0143-7496(99)00039-1.

[113] M.J. Yim, Y. Li, K. Moon, K.W. Paik, C.P. Wong, Review of recent advances in electrically conductive adhesive materials and technologies in electronic packaging, J. Adhes. Sci. Technol. 22 (2008) 1593-1630, http://dx.doi.org/10. 1163/156856108X320519.

[114] M.N. Kirikova, E.V. Agina, A.A. Bessonov, A.S. Sizov, O.V. Borshchev, A.A. Trul, A.M. Muzafarov, S.A. Ponomarenko, Direct-write printing of reactive oligomeric alkoxysilanes as an affordable and highly efficient route for promoting local adhesion of silver inks on polymer substrates, J. Mater. Chem. C 4 (2016) 2211-2218, http://dx.doi.org/10.1039/C5TC03497C.

[115] I. Hutchinson, Raw materials for UV curable inks, in: Chem. Inkjet Inks, 2009, pp. 177-201, http://dx.doi.org/10.1142/9789812818225_0010.

[116] G. Odian, Radical chain polymerization, in: Princ. Polym., 4th edition, Wiley-Interscience, 2004, pp. 198-332.

[117] M.P. Stevens, Free radical polymerization, in: Polym. Chem., 3rd edition, Oxford University Press, 1999, pp. 167-201.

[118] K. Studer, P. Nesvadba, T. Jung, J. Benkhoff, K. Powell, C. Lordelot, Novel curing agents: thermal radical initiators as viable alternatives to peroxides, Prog. Org. Coat. 61 (2008) 119-125, http://dx.doi.org/10.1016/j.porgcoat. 2007.07.034.

[119] X. Yue, Conductive ink composition (EP 1207726B1), 2002.
[120] Q. Shang, S. Hao, J. Zhang, J. Gong, F. Wang, Y. Wu, S. Gu, Investigation on constitution of electrical conductive adhesives fitting for UV-thermal dual curing, J. Adhes. Sci. Technol. 29 (2015) 910-923, http://dx.doi.org/10.1080 01694243.2015 .1009723$.

[121] K. Eiroma, L. Hakola, J. Hast, A. Maaninen, J. Petäjä, UV curing for printed electronics, RadTech Rep. Sep/Oct (2007) 31-34.

[122] L.Y. Gu, G.Y. Wang, D.D. Wang, Research on the conductivity of UV-curable conductive ink, in: Appl. Mech. Mater., Trans Tech Publications, 2014, pp. 51-54, http://dx.doi.org/10.4028/www.scientific.net/AMM.469.51.

[123] S.M. Noh, J.W. Lee, J.H. Nam, K.H. Byun, J.M. Park, H.W. Jung, Dual-curing behavior and scratch characteristics of hydroxyl functionalized urethane methacrylate oligomer for automotive clearcoats, Prog. Org. Coat. 74 (2012) 257-269, http://dx.doi.org/10.1016/j.porgcoat.2012.01.002.

[124] R. Oldenzijl, Electrically conductive UV-curable ink (US20080250972A1), 2008.

[125] G. Battersby, UV\&EB opportunities in printed electronics-summary report, RadTech Rep. Sep/Oct (2007) 14-18.

[126] Y. Farraj, M. Bielmann, S. Magdassi, Inkjet printing and rapid ebeam sintering enable formation of highly conductive patterns in roll to roll process, RSC Adv. 7 (2017) 15463-15467, http://dx.doi.org/10.1039/C7RA00967D.

[127] S.C. Lapin, Comparison of UV and EB technology for printing and packaging applications, RadTech Rep. Sep/Oct (2008) 27-35.

[128] X. Xia, C. Xie, S. Cai, Z. Yang, X. Yang, Corrosion characteristics of copper microparticles and copper nanoparticles in distilled water, Corros. Sci. 48 (2006) 3924-3932, http://dx.doi.org/10.1016/j.corsci.2006.04.007.

[129] S. Xu, Evaluating Thermal and Mechanical Properties of Electrically Conductive Adhesives for Electronic Applications, Virginia PolyTechnic Institute and State University, 2001.

[130] B.M. Amoli, E. Marzbanrad, A. Hu, Y.N. Zhou, B. Zhao, Electrical conductive adhesives enhanced with high-aspect-ratio silver nanobelts, Macromol. Mater. Eng. 299 (n.d.) 739-747. doi:10.1002/mame.201300295.

[131] C. Li, Q. Li, L. Cheng, T. Li, H. Lu, L. Tang, K. Zhang, S.E., J. Zhang, Z. Li, Y. Yao, Conductivity enhancement of polymer composites using high-temperature short-time treated silver fillers, Compos. A: Appl. Sci. Manuf. 100 (2017) 64-70, http://dx.doi.org/10.1016/j.compositesa.2017.05.007.

[132] L. Vescovo, M. Sangermano, R. Scarazzini, G. Kortaberria, I. Mondragon, In-situ-synthetized silver/epoxy nanocomposites: electrical characterization by means of dielectric spectroscopy, Macromol. Chem. Phys. 211 (2010) 1933-1939, http://dx.doi.org/10.1002/macp.201000138.

[133] J.R. Nair, V.S. Ijeri, C. Gerbaldi, S. Bodoardo, R. Bongiovanni, N. Penazzi, Nove self-directed dual surface metallisation via UV-curing technique for flexible polymeric capacitors, Org. Electron. 11 (2010) 1802-1808, http://dx.doi.org/ 10.1016/j.orgel.2010.08.003.

[134] M. Sangermano, I. Roppolo, V.H.A. Camara, C. Dizman, S. Ates, L. Torun, Y. Yagci, Polysulfone/metal nanocomposites by simultaneous photoinduced crosslinking and redox reaction, Macromol. Mater. Eng. 296 (2011) 820-825, http://dx.doi.org/10.1002/mame.201000440.

[135] W.D. Cook, Q.D. Nghiem, Q. Chen, F. Chen, M. Sangermano, Simultaneous photoinduced silver nanoparticles formation and cationic polymerization of divinyl ethers, Macromolecules 44 (2011) 4065-4071, http://dx.doi.org/10. $1021 / \mathrm{ma200575n}$.

[136] A. Chiolerio, I. Roppolo, M. Sangermano, Radical diffusion engineering: tailored nanocomposite materials for piezoresistive inkjet printed strain measurement, RSC Adv. 3 (2013) 3446-3452, http://dx.doi.org/10.1039/ C3RA22159H.

[137] M. Layani, I. Cooperstein, S. Magdassi, UV crosslinkable emulsions with silver nanoparticles for inkjet printing of conductive 3D structures, J. Mater. Chem. C 1 (2013) 3244-3249, http://dx.doi.org/10.1039/C3TC30253A.

[138] I. Cooperstein, M. Layani, S. Magdassi, 3D printing of porous structures by UV-curable $\mathrm{O} / \mathrm{W}$ emulsion for fabrication of conductive objects, J. Mater. Chem. C 3 (2015) 2040-2044, http://dx.doi.org/10.1039/C4TC02215G.

[139] Z. Żołek-Tryznowska, Additives for ink manufacture, in: Print Polym., 2016, pp. 57-66, http://dx.doi.org/10.1016/B978-0-323-37468-2.00004-X.

[140] H. Becker, H. Vogel, The role of hydroquinone monomethyl ether in the stabilization of acrylic acid, Chem. Eng. Technol. 29 (2006) 1227-1231, http://dx.doi.org/10.1002/ceat.200500401.

[141] S.C. Ligon, B. Husár, H. Wutzel, R. Holman, R. Liska, Strategies to reduce oxygen inhibition in photoinduced polymerization, Chem. Rev. 114 (2014) 577-589, http://dx.doi.org/10.1021/cr3005197.

[142] H. Palza, Antimicrobial polymers with metal nanoparticles, Int. J. Mol. Sci. 16 (2015) 2099-2116, http://dx.doi.org/10.3390/ijms16012099.

[143] B. Weyershausen, K. Lehmann, Industrial application of ionic liquids as performance additives, Green Chem. 7 (2005) 15-19, http://dx.doi.org/10. 1039/B411357H. 